Article

\title{
The Influence of Building Airtightness on Airflow in Stairwells
}

\author{
Philip Mckeen ${ }^{1}$ and Zaiyi Liao ${ }^{1,2, *}$ \\ 1 Department of Architectural Science, Ryerson University, Toronto, M5B 2K3, Canada; pmckeen@ryerson.ca \\ 2 School of Hydraulic and Environmental Engineering, China Three Gorges University, Yichang, 443000, China \\ * Correspondence: zliao@ryerson.ca
}

Received: 14 July 2019; Accepted: 9 September 2019; Published: 24 September 2019

\begin{abstract}
Airflow into stairwells due to stack effect is a concern affecting fire safety, energy performance, and indoor air quality. Stack effect in tall buildings can create significant pressure differentials in vertical shafts when differences in outdoor and indoor temperature exist. The pressure differentials drive air through openings or gaps in walls and floors. Vertical shafts, consisting of stairs and elevators, may transport significant volumes of air. During heating season, this results in the infiltration of cold air at lower floors and the exhaust of warm air on the upper floors. Correspondingly, it results in the spread of air and potential contaminants within the building. Stack effect driven airflow will change according to size and distribution of leakage paths. The size of leakage areas can be approximated by a cross-sectional area of an orifice that would allow equivalent flow. This leakage area is dependent on construction material, workmanship, and even operation, as openings from windows and doors equate to large orifices. A building's composition of these leakage areas can greatly impact the effective area and airflow. The effect of openings from stairwell doors can change the Neutral Pressure Plane location (NPP), altering airflow patterns within a building. This paper investigates the influence of effective area on airflow within stairwells for multi-unit residential buildings (MURB) due to stack effect. A range of parameters reflective of industry standards are evaluated using network modeling and computational fluid dynamics (CFD). Parametric analysis is used to determine the sensitivity to which they affect airflow between building and stairwells. The effect of airflow within vertical shafts has consequences on indoor air quality (IAQ) and smoke spread, energy efficiency, and thermal comfort. The benefit of reducing leakage in buildings can be understood by comparing the quantity and patterns in airflow in and out of stairwells. Improving air tightness of the building envelope or vertical shafts can have a significant impact on airflow.
\end{abstract}

Keywords: airflow; leakage; stairwell; stack; airtightness

\section{Introduction}

Airtightness of buildings can affect the airflow within stairwells and vertical shafts. Leaks and openings allow airflow when subject to pressure differentials created by stack effect, wind, heating, ventilation, and air conditioning (HVAC), fire, and other sources. Increasing airtightness or reducing the size of leaks will reduce the infiltration of air and spread of contaminants within the building. The trend towards achieving tighter buildings has the benefit of reducing the volumetric airflow exchange within buildings. Airflow can be quantified mathematically when leakage characteristics and pressure differentials are known. However, leakage characteristics of buildings vary depending on building design and construction.

Evaluating a range of leakage characteristics using parametric analysis can determine the influence of building airtightness on airflow into stairwells. An idealized model of a 10-storey multi-unit residential buildings (MURB) was developed utilizing a range of parameters derived from field 
experiments and industry testing. The influence of airtightness on airflow within stairwells can be evaluated using analytical equations, network modeling, and computational fluid dynamics (CFD). Verification and validation of model parameters were performed to compare with mathematical equations and experimental results. Quantification of airflow demonstrates the importance of airtightness, with leaky buildings resulting in airflow rates orders of magnitude higher.

\subsection{Literature Review}

Airflow within buildings due to airtightness and stack effect has been a topic of interest to the field of fire safety, HVAC, indoor air quality, energy efficiency, and building envelope performance. Since 1960, the complexity of airflow through the building assembly was investigated by Tamura and others. Field experiments using controlled pressure differentials measured the influence of building materials and geometries on airflow patterns. This led to the development of analytical equations and mathematical models capable of predicting the airflow and spread of contaminants within buildings [1].

Air leakage of walls, doors and building components has been conducted by both experimental research [2-5] and industry testing [5,6]. Experiments by Gulay demonstrated a significant range of airtightness amongst MURBs within Canada. Such studies provide guidance regarding the range of leakage area one might expect. Furthermore, leakage characteristics of constructed buildings can often change significantly from the intended design and influence airflow patterns.

The use of HVAC and pressurization systems can influence airflow and counteract the effect of leakage in buildings. While pressurization is utilized in many buildings today, such systems are absent in a large proportion of existing building stock. Additional concerns exist regarding the inadequacy of HVAC and pressurization systems and the improper maintenance and operational circumstances that may reduce their effectiveness [7].

In many existing MURBs in Canada, make-up air units (MAU) supply the corridor with fresh air. The pressurization is intended to drive airflow into suites through leakage paths around entrance doors. Designs do not often account for environmental effects such as stack and wind, airtightness or compartmentation [8]. However, leakage paths within stairwells often result in large proportions of airflow entering the stairwells.

Pressurization testing of a 13-storey MURB found that for corridor supplied air intended for suites, only $20 \%$ reached suites and a large proportion was able to enter vertical shafts: $29 \%$ stairwell doors, $41 \%$ elevator doors. Further airflow analysis using tracer gas noted a large discrepancy in airflow entering suites on the lower and upper floors of a building [8]. The building was subject to outdoor temperatures of $8{ }^{\circ} \mathrm{C}$ and wind speed of $3.1 \mathrm{~km} / \mathrm{h}$. Attributed partially to stack effect, suites on lower floors received approximately 5 to $13 \mathrm{~L} / \mathrm{s}$, significantly less than what may be required from ASHRAE Standard 62.1 IAQ standards. Suites on upper floors received upwards of $70 \mathrm{~L} / \mathrm{s}$. This demonstrates that design specifications, when subject to environmental conditions, may fail to meet intended results.

Several computer-based models have been developed to analyze airflow within buildings. Network models are useful in analyzing the interaction of airflow between zones of a building on a macroscopic, whole-building level [9]. Network models represent buildings using an array of nodes, with properties of pressure, temperature, and leakage area. At node locations, conservation equations determine the movement of gas through leaks due to pressure. As network models are simple and inexpensive computationally, they allow for detailed parametric studies [10]. CONTAM is an air quality and ventilation analysis software that utilizes network models and can be used to calculate airflow and pressure distributions [9].

CFD allows for detailed airflow analysis and visualization within zones of a building. Evolution of CFD models utilizes differential equations of mass, momentum, and energy to predict the fluid flow on a detailed scale over time. CFD calculations change amongst a fine grid within the model geometry, allowing gas properties of pressure and temperature to be simulated throughout zones with accuracy, but with higher computational cost [11]. Fire Dynamics Simulator (FDS) is a CFD software capable of solving Navier-Stokes equations for low-Mach, thermally driven flow, used extensively 
in fire and smoke simulations [12]. FDS version 6.7.1 was utilized to visualize airflow patterns, the transient environment influence, and to compare results.

\subsection{Stack Effect}

Stack effect describes the hydrostatic pressure differential due to differences in interior and ambient air density. When the air in a vertical shaft is warmer and less dense than the ambient environment, buoyant forces exert outward pressure at the top of the shaft. Conversely, colder ambient air will exert inward pressure towards the bottom of the shaft. When leakage paths exist, stack driven airflow will occur.

Stack effect is a dominant force driving air movement in tall buildings during cold climates during winter periods $[8,13]$. The magnitude of stack pressure is a function of the building height and ambient temperature. Increasing the height and temperature difference can lead to significant pressures differentials. The stack pressure within a vertical shaft can be determined for a height from Equation (1):

$$
\Delta P_{s}=\rho_{o}\left(\frac{T_{i}-T_{0}}{T_{i}}\right) g\left(H_{N P P}-H_{r e f}\right)
$$

$\Delta P_{S}=$ pressure change due to stack effect, $\mathrm{Pa} ;$

$\rho_{o}=$ outdoor air density, $\mathrm{kg} / \mathrm{m}^{3}$;

$T_{0}=$ absolute temperature of outside air, $\mathrm{K}$;

$T_{i}=$ absolute temperature of inside air, $\mathrm{K} ;$

$g=$ gravitational acceleration, $9.81 \mathrm{~m} / \mathrm{s}^{2}$;

$H_{N P P}=$ height of neutral pressure plane, $\mathrm{m}$;

$H_{\text {ref }}=$ height above neutral pressure plane, $\mathrm{m}$.

The location of the Neutral Pressure Plane (NPP) occurs where the hydrostatic pressure in a vertical shaft equals the ambient pressure. When leakage is equally distributed along the vertical axis, the NPP will occur at mid-height. The strength of stack effect increases as the distance from the NPP increases. In cold ambient conditions, the rise of warm interior air will create a negative pressure differential below the NPP, increasing in strength towards the bottom of the shaft. Where leakage paths exist, infiltration of outdoor air will occur beneath the NPP, entering the shaft. The rise of air in shafts creates positive pressure above the NPP, increasing in strength towards the top of the shaft. A vertical shaft within a multi-story building can allow air flow from the shaft to enter floors above the NPP. Due to this, air and contaminants originating from the ground floor may readily travel to the floors above the NPP. Since the strength of stack effect is greatest the further from the NPP, the top floor will receive the most stack driven airflow.

Where building leakage is unevenly distributed along the vertical axis, the location of the NPP will change. Increased leakage openings towards the bottom of the building will raise the NPP above mid-height. Thus, a rise in the NPP location can prevent the spread of contaminants to certain floors. Variation in vertical leakage of a building changes the airflow patterns of a building subject to stack effect. Figure 1 shows the stack pressure acting on a vertical shaft for various outdoor temperatures, when leakage distribution is uniform or dominant towards the top or bottom. 


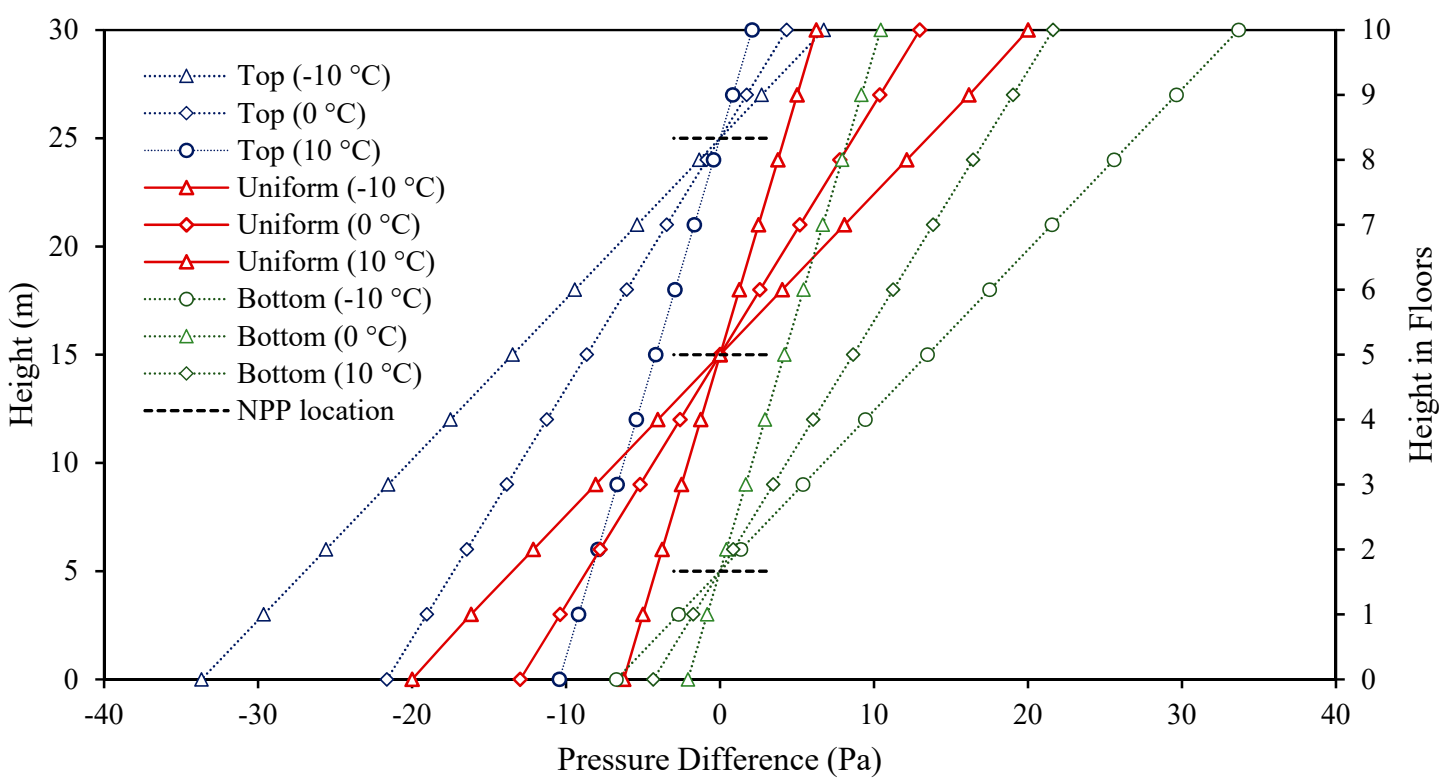

Figure 1. Stack pressure of a vertical shaft of $20^{\circ} \mathrm{C}$ for variations in ambient temperature $\left(-10,0,10^{\circ} \mathrm{C}\right)$ and leakage distribution (top, uniform, bottom).

\subsection{Airflow through Buildings}

Buildings are made up of numerous compartments connected by leakage paths. Airflow within a building is analogous to the flow through a complex system of pipes and orifices [14]. Airflow through a series of leakage areas can be analyzed using the effective flow area concept. The effective flow area is defined as the cross-sectional area capable of producing equivalent airflow. Many detailed studies of effective flow within building compartments have been conducted [1,15]. A pressure differential within a vertical shaft can result in airflow through leakage paths within the exterior, corridors, and shafts walls, as depicted in Figure 2.

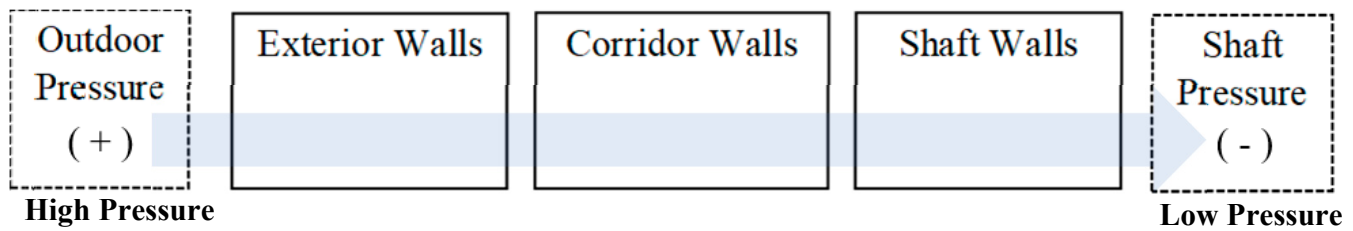

Figure 2. Illustration showing the airflow through building compartments when vertical shafts are subject to stack pressure differentials.

The airflow paths can be in parallel with one another, in series, or both. The effective flow area of parallel paths is a summation of the individual leakage areas. The effective flow area of parallel paths is determined by Equation (2).

$$
A_{e}=\sum_{i=1}^{n} A_{i}
$$

$A_{e}=$ effective flow area, $\mathrm{m}^{2} ;$

$A_{i}=$ leakage area $\mathrm{i}, \mathrm{m}^{2}$.

The effective flow area for a series of leaks can be determined by Equation (3). This equation demonstrates that the effective area is influenced by the most restrictive path in a series of leaks. 
Thus, impact of a large opening in a series of small openings will be insignificant on the net airflow. Alternatively, a small opening, in a series of large openings will greatly restrict airflow.

$$
A_{e}=\left(\sum_{i=1}^{n} \frac{1}{A_{i}^{2}}\right)^{-\frac{1}{2}}
$$

The airflow resulting from a leak can be estimated using analytical equations, including the commonly used flow equation appropriate for sharp-edged orifices (Equation (4)). The orifice can be defined with a cross-sectional area perpendicular to the flow of air, or the effective flow area, $A_{e}$.

$$
\dot{V}=C_{d} A_{e} \sqrt{\frac{2 \Delta p}{\rho}} .
$$

$\dot{V}=$ volumetric flow rate, $\frac{\mathrm{m}^{3}}{\mathrm{~s}}$

$C_{d}=$ discharge coefficient;

$A_{e}=$ effective flow area, $\mathrm{m}^{2} ;$

$\rho=$ density of gas, $\mathrm{kg} / \mathrm{m}^{3}$;

$\Delta p=$ pressure differential, $\mathrm{Pa}$.

The orifice equation is based on Bernoulli's equation, which applies to frictionless flows. A flow coefficient is used to account for friction and dynamic losses from laminar and turbulent flow. The flow can be approximated based on the leak geometry. For cracks and narrow openings common in walls and floors, it is common to use a $C_{d}$ range between 0.6 to 0.7 . Large openings can expect turbulence and the presence of stationary vortices and $C_{d}$ of 0.35 is suggested [15]. These equations, when tailored with the proper coefficients, have shown good agreement with experiments and deemed acceptable for the study of air movement and smoke spread in buildings [15]. The effective flow area of a building envelope, corridors, and stairwell walls can affect the airflow into vertical shafts. Studies conducted by Klote estimated significant increases of airflow through stairwells when open doors and other openings exist [16]. Thus, the airtightness of the system of compartments can influence the airflow magnitude.

Building airtightness has been studied extensively and continues to evolve in industry applications and testing. Air leakage testing of envelopes determines the airflow rate at specific pressure differentials. The power law equation can describe this relationship (Equation (5)). A pressure exponent is used to account for the nature of the flow, which will range from 0.5 for turbulent to 1.0 for laminar [17]. A building, with an array of leaks, will be composed of a mixture of flows, and 0.65 is often used to describe the building envelope [18]. For an orifice type opening, the pressure exponent of 0.5 is used instead, as mostly turbulent flow is expected and closely resembles the orifice equation.

$$
Q=C(\Delta p)^{n}
$$

$Q=$ volumetric flow rate, $\mathrm{m}^{3} / \mathrm{s},(1000 \mathrm{~L} / \mathrm{s})$;

$C=$ flow coefficient;

$n=$ pressure coeffecient;

$\Delta p=$ pressure differential, $\mathrm{Pa}$.

\section{Materials and Methods}

It is necessary to determine the leakage area of building components to determine the resulting airflow. This can be challenging because the airtightness and design of buildings varies significantly. Identifying a range of airtightness values existing and new buildings are likely to fall within allows simulations to realistically determine the influence of airtightness on airflow. A pressurization test of building walls and components can be used to quantify appropriate leakage areas for buildings. 
Early studies by Tamura and Shaw analyzed the air leakage in several high-rise office towers. Envelope leakage was defined as tight, average, and leaky and airflow measured $0.5,1.5$, and $3.0 \mathrm{~L} / \mathrm{s} / \mathrm{m}^{2}$ at $75 \mathrm{~Pa}$ respectively. Large variation between the same building and construction material is expected and can often be attributed to workmanship [19]. Field investigations of air leakage rate through exterior walls of several MURBs in Canada ranged from 0.5 to $10.9 \mathrm{~L} / \mathrm{s} / \mathrm{m}^{2}$ at $50 \mathrm{~Pa}$ [5]. A large study of over 500 buildings in North America constructed from 1950 to present, including MURBs, ranged from 0.2 to as high as $25 \mathrm{~L} / \mathrm{s} / \mathrm{m}^{2}$ when measured at $75 \mathrm{~Pa}$ [20]. The average airtightness was $3.65 \mathrm{~L} / \mathrm{s} / \mathrm{m}^{2}$ and was noted to generally improve for newer buildings. Implementation of air tightness standards is becoming increasingly common. ASHRAE 90.1-2016 requires airtightness minimum of $2.0 \mathrm{~L} / \mathrm{s} / \mathrm{m}^{2}$ at $75 \mathrm{~Pa}$. Energy Star requires an airtightness of $1.5 \mathrm{~L} / \mathrm{s} / \mathrm{m}^{2}$ at $50 \mathrm{~Pa}$. International Green Construction Code (IGCC) proposes a target of $1.27 \mathrm{~L} / \mathrm{s} / \mathrm{m}^{2}$ at $75 \mathrm{~Pa}$ [6].

Results of airtightness testing can be used to approximate leakage areas of building components using Equation (4) for a specified pressure differential. This can be useful for describing the leakiness of individual building components. Typical leakage areas of commercial buildings derived from field experiments performed by the National Research Council of Canada [2] are described in Table 1.

Table 1. Air leakage of surfaces.

\begin{tabular}{cccc}
\hline Wall Component & Tightness Description & $\begin{array}{c}\text { Typical Leakage Area } \\
\text { (Tamura and Shaw) }\end{array}$ & $\begin{array}{c}\text { Value Selected for Simulation } \\
\text { Equivalent Air Leakage Area }\end{array}$ \\
\hline \multirow{3}{*}{ Envelope } & Tight & $0.5 \mathrm{~cm}^{2} / \mathrm{m}^{2}$ & $1.5 \mathrm{~cm}^{2} / \mathrm{m}^{2}$ \\
& Average & $1.7 \mathrm{~cm}^{2} / \mathrm{m}^{2}$ & $3.0 \mathrm{~cm}^{2} / \mathrm{m}^{2}$ \\
& Loose & $3.5 \mathrm{~cm}^{2} / \mathrm{m}^{2}$ & $6.0 \mathrm{~cm}^{2} / \mathrm{m}^{2}$ \\
& Very Loose & $12.0 \mathrm{~cm}^{2} / \mathrm{m}^{2}$ & $12.0 \mathrm{~cm}^{2} / \mathrm{m}^{2}$ \\
\hline
\end{tabular}

The leakage values selected for use in the building model were modified from those presented by Tamura. The leakage values of $1.5,3.0,6.0$, and $12.0 \mathrm{~cm}^{2} / \mathrm{m}^{2}$ are presented in Figure 3 comparing the airflow calculated using the orifice equation. The selected values better reflect the wide distribution of airtightness observed in numerous MURBs in Canada. Additionally, the selected leakage areas follow consistent increases, allowing for better comparison of results from model simulations.

In Figure 3, several envelope leakage studies are included to illustrate the wide range of leakage encountered in existing MURBs and tall buildings. The airflow was calculated utilizing the orifice equation (Equation (4)), with a pressure exponent of 0.5 and discharge coefficient of 0.65 . In addition, also included are reference to leakage standards defined in ASHRAE 90.1-2016 and IGCC, calculated utilizing the power law equation (Equation (5)) with a pressure exponent of 0.65 . While the pressure exponent can affect the airflow significantly at higher pressures, the orifice equation can be utilized reasonably well to describe airflow within a range of pressures.

Arguments have been made to suggest that accurate leakage is best described by pressure and airflow as inputs, as opposed to leakage areas. Leakage areas described in the literature are often based on limited data and vary by orders of magnitude [21]. The ability to utilize reference pressure is possible in many airflow software today such as CONTAM. While the use of leakage area is used in these simulations, they provide a reasonable representation of airflow for various levels of airtightness as seen in Figure 3.

The leakage area of a building envelope can vary due to its construction as well as surface area. Larger surface areas will yield increased leakage area. A building's envelope surface area is a function of geometry and influenced by the floorplate area and aspect ratio. Since MURBs are often constructed with various aspect ratios, leakage area will vary. However, the majority of MURBs conform to common aspect ratios. Floor plate sizes are often limited by building codes, municipalities, and design requirements. The expected variation in exterior wall surface area for MURBs can be made apparent from Figure 4. 


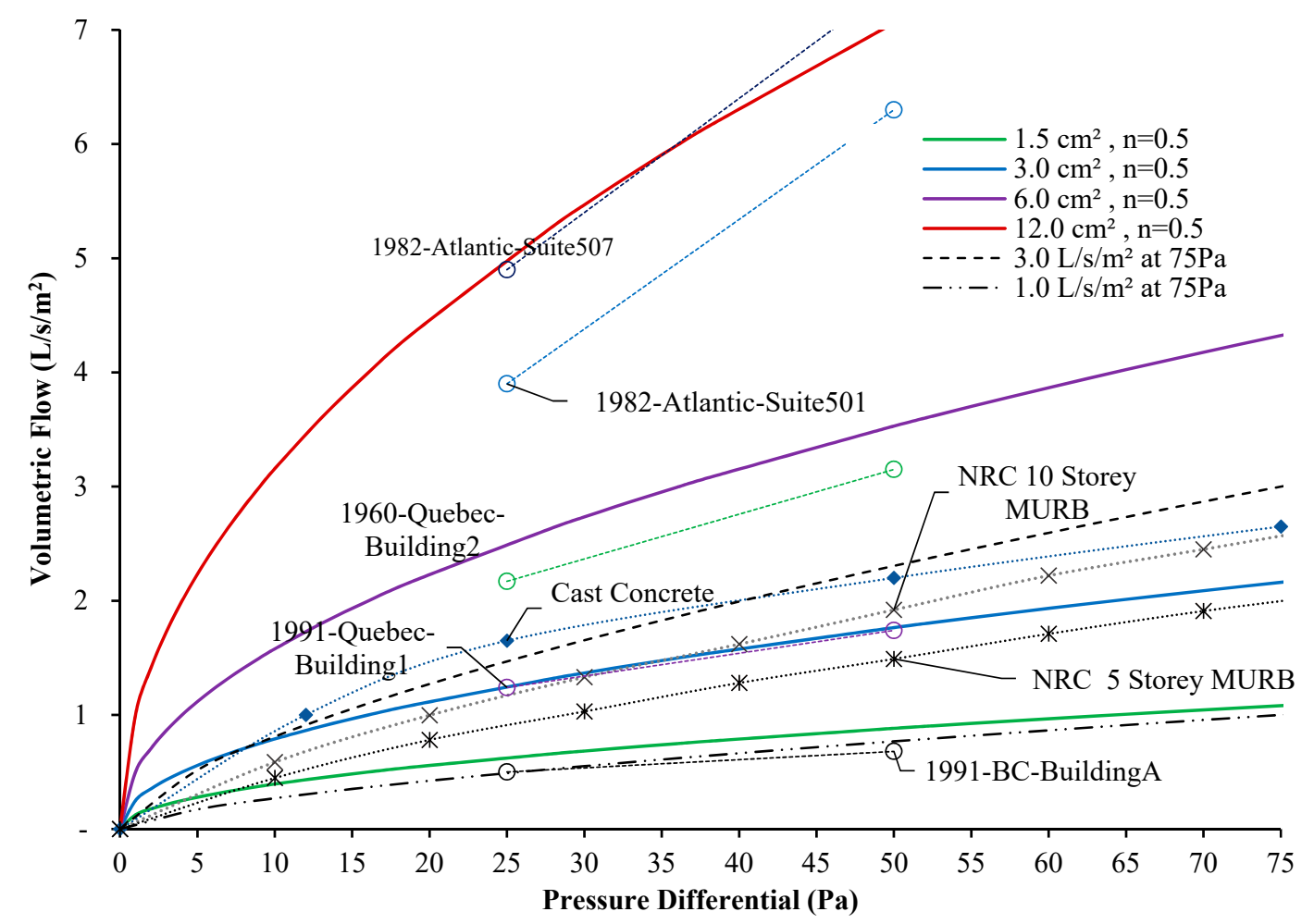

Figure 3. Airflow through building envelopes under pressure differential for specified leakage areas, air leakage standards, and field measurements.

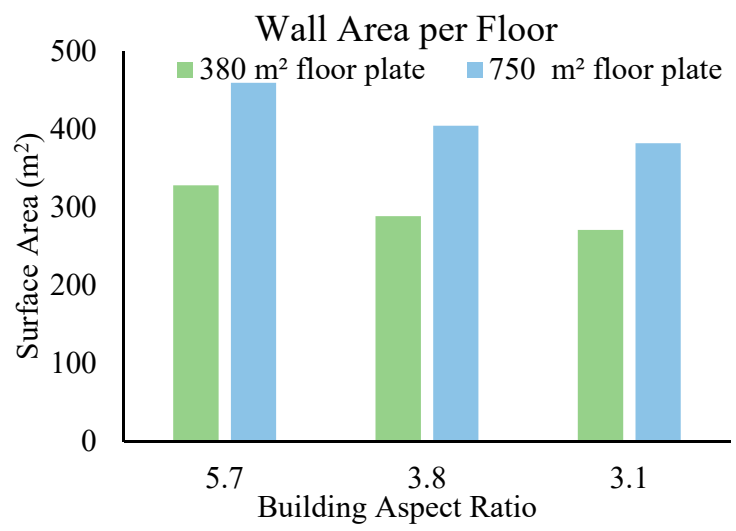

Figure 4. Wall surface area per floor for various building aspect ratios with a rectangular plan.

A building with a floor plate area of $380 \mathrm{~m}^{2}$, aspect ratio of 1.9, and a floor to floor height of $3 \mathrm{~m}$, would have an exterior wall surface area of $246 \mathrm{~m}^{2}$ per floor. By contrast, an aspect ratio of 3.1 would result in a wall surface area of $270 \mathrm{~m}^{2}$ for the same floor plate area. Many specific design factors will influence the actual surface area. However, it can be generally assumed that the variation in wall surface area can be within a known range for buildings of typical design.

\subsection{Airtightness of Stairwell}

Leakage paths through the stairwell consist of the wall surface area and door. The stairwell wall does not often account for a substantial source of leakage when constructed with cast concrete and free from large cracks. Where significant cracks exist, or where concrete block or porous materials exist, this could allow significantly more airflow through. The dimensions of a stairwell are often similar, varying somewhat to account for different stair configurations (such as scissor or conventional). A stairwell shaft containing scissor stairs would have a wall surface area of approximately $72 \mathrm{~m}^{2}$ per floor if the 
plan dimensions were $8 \times 3 \mathrm{~m}$. Assuming a leakage area of $1.1 \mathrm{~cm}^{2} / \mathrm{m}^{2}$ for a concrete shaft, the effective leakage area that could be expected from stairwell walls would be approximately $0.008 \mathrm{~m}^{2}$ per floor.

The existence of doors, even when closed, generally present a significantly greater leakage path. The detailed geometry of closed doors is not considered in the general orifice Equation (6). The narrow orifice tendency towards laminar flow can allow for a greater airflow compared to a circular orifice of equal cross-sectional area. However, as the gap becomes increasingly narrow, a reduction in airflow will occur due to friction and viscosity. Gross and Haberman developed an analytical solution to improve prediction of airflow through narrow gaps around door edges [4]. Equations (6) and (7) account for the influence of viscosity which contributes to observations of the volume flow rate varying within three distinct ranges of pressure. At low dimensionless pressure (Region 1), the volume flow rate varies linearly. At high dimensionless pressure (Region 3), the volume flow rate varies with the square root of pressure.

$$
\begin{gathered}
N P=\frac{K_{N P} \Delta p D_{h}{ }^{2}}{\rho v^{2}}\left(\frac{D_{h}}{x}\right)^{2}, \\
N Q=R_{e}\left(\frac{a}{n}\right) .
\end{gathered}
$$

$N P=$ dimensionless pressure difference;

$N Q=$ dimensionless flow rate;

$R_{e}=$ Reynolds number;

$a=$ thickness of gap in direction perpendicular to flow, $\mathrm{m}$;

$x=$ depth of gap in flow direction, $\mathrm{m}$;

$v=$ kinematic visosity, $\mathrm{m}^{2} / \mathrm{s}$;

$K_{N P}=1.0$;

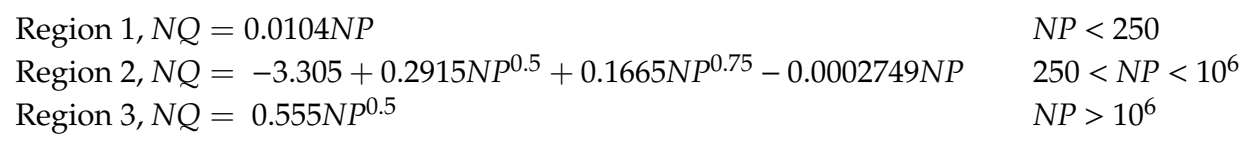

The volumetric flow can be determined by substituting the appropriate values of NQ into Equation (8), suitable for straight gaps common in doors. This equation accounts for the straight gap properties such as the depth and width. Further modifications of this equation can account for gaps with bends, to account for a variety of door and frame properties, including gaskets. These are not utilized in this study, but it is important to realize how the detailed geometry of an orifice can influence the volumetric flow rate.

$$
\dot{V}=\frac{K_{q} v x L N Q}{D_{h}} .
$$

$\dot{V}=$ volumetric flow rate, $\mathrm{m}^{3} / \mathrm{s}$;

$N Q=$ dimensionless flow;

$L=$ length of gap, m;

$D_{h}=$ hydraulic area, m;

$x=$ depth of gap in flow direction, $\mathrm{m}$;

$K_{q}=1.0$.

Experiments were carried out by Gross and Haberman to evaluate the airflow through a variety of doors and frames. The airflow through these doors demonstrated that the cross-sectional orifice area is not an absolute indication of airflow as doors with more leakage area were not necessarily leakier [22]. Gross and Haberman's gap method was demonstrated to provide increased accuracy in predicting door leakage than the simple orifice Equation (6).

An analysis of how the results of the general orifice equation and gap equation compare can be seen in Table 2 and Figure 5. Three doors of standard $2.2 \times 0.91 \mathrm{~m}$ dimension with straight through 
gaps of $2 \mathrm{~mm}\left(125 \mathrm{~cm}^{2}\right), 3 \mathrm{~mm}\left(186 \mathrm{~cm}^{2}\right), 5 \mathrm{~mm}\left(311 \mathrm{~cm}^{2}\right)$ are compared. For a door with a $3 \mathrm{~mm}$ gap subject to a pressure differential of $25 \mathrm{~Pa}$, the gap method estimates a volumetric flow of $0.84 \mathrm{~m}^{3} / \mathrm{s}$. For the same effective area, the orifice equation yields an airflow of $0.077 \mathrm{~m}^{3} / \mathrm{s}$ for a 25 Pa differential. It can be noted for very narrow gaps at low pressures, the gap method yields significantly lower airflow (Figure 5).

Table 2. Comparison of leakage area and volumetric airflow for closed doors, using the orifice equation, gap method, and experimental measurements with a 25 Pa pressure differential.

\begin{tabular}{cccc}
\hline \multirow{2}{*}{ Door Gap } & Method & $A_{\boldsymbol{e}}$, Effective Area $\left(\mathbf{m}^{\mathbf{2}}\right)$ & $\dot{\boldsymbol{V}}$, Volumetric Flow $\left(\mathbf{m}^{\mathbf{3}} \mathbf{s}\right)$ \\
\hline \multirow{2}{*}{$2 \mathrm{~mm}$} & Orifice Equation (FDS) & 0.0125 & 0.052 \\
& Gap Method & 0.0125 & 0.045 \\
\hline \multirow{2}{*}{$3 \mathrm{~mm}$} & Orifice Equation (FDS) & 0.0187 & 0.077 \\
& Gap Method & 0.0187 & 0.084 \\
\hline \multirow{2}{*}{$5 \mathrm{~mm}$} & Orifice Equation (FDS) & 0.0311 & 0.129 \\
& Gap Method & 0.0311 & 0.157 \\
\hline \multirow{2}{*}{ Varies } & Experiment & 0.0190 & 0.061 \\
& Experiment & 0.0255 & 0.127 \\
& Experiment & 0.0200 & 0.076 \\
& Experiment & 0.0177 & 0.071 \\
& Experiment & 0.0287 & 0.104 \\
\hline
\end{tabular}

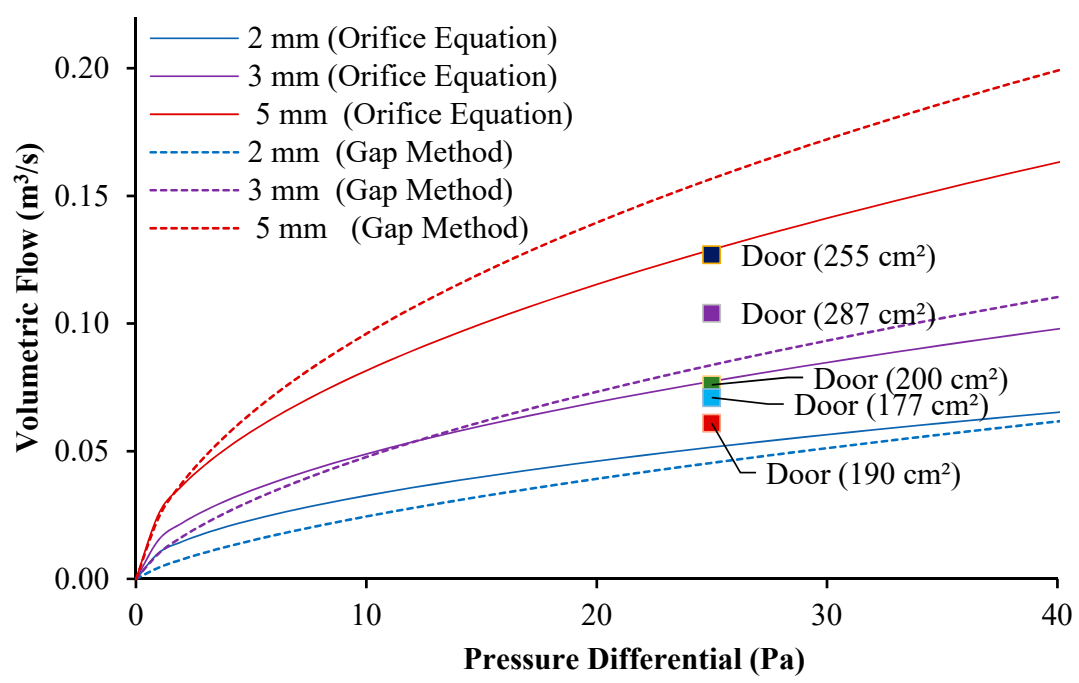

Figure 5. Airflow through closed doors from the orifice equation, gap method, and experimental measurements.

\subsection{Airflow in Stairwells}

Stairwell shafts and stairs affect the uniformity of airflow and pressure [23]. The geometry and friction resist the flow of air and reduce the volumetric flow. The effect of friction can be significant in mechanical pressurization of stairwells, which utilizes high velocity flow. For applications without mechanical pressurization, the effect of resistance is minor as the airspeed is low. However, in situations where stairwell doors are open, airflow velocity will be increased and the restrictions to airflow can be observed.

Pressure loss due to friction can be calculated with the geometrical properties of the shaft, including the hydraulic area, velocity of airflow in the shaft, and the friction factor derived from the surface 
texture. Equation (9) demonstrates that velocity is a significant proponent of the pressure loss, and that the friction of the stairwell will be more significant at high velocities.

$$
\Delta p_{f}=f \frac{L}{D_{h}} \frac{\rho U^{2}}{2} .
$$

$\Delta p_{f}=$ pressure loss in shaft, per floor;

$f=$ dimensionless friction factor of shaft;

$L=$ shaft height, $\mathrm{m}$;

$D_{h}=$ hydraulic area, $\mathrm{m}$;

$U=$ average velocity inside shaft;

$\rho=$ density of gas inside shaft.

Stairwells are similar to ducts and shafts, so the effect of friction can be calculated in a similar manner. Analytical experiments conducted by Tamura and Shaw elaborated Equation (9) to account for additional friction from stair treads [3]. The findings indicated friction factors for a variety of stairwell types, including conventional and scissor, open and closed treads. The friction factor for conventional closed treads and scissor type are approximately 32 and 15 respectively. The effective area of a stairwell can be determined based on Equation (10).

$$
\frac{A_{o}}{A_{s}}=\frac{1}{C \sqrt{f \frac{L}{D_{h}}}} .
$$

$A_{o}=$ equivalent area, $\mathrm{m}^{2}$;

$A_{s}=$ cross sec tional area of shaft, $\mathrm{m}^{2}$;

$L=$ shaft height, $\mathrm{m}$;

$D_{h}=$ hydraulic area, $\mathrm{m}$;

$f=$ dimensionless friction factor of shaft;

$C=$ dimensionless flow coeffecient (varies depending on opening, 0.6 is often used).

The effect of stairs on airflow was compared to an open shaft using calculations, network simulation, and FDS (Figure 6). A 10-storey shaft with equally distributed door openings was analyzed. The shaft had no exterior envelope and an outdoor temperature of $-5^{\circ} \mathrm{C}$, resulting in stack pressure. The volumetric airflow entering the open stairwell door at the 1 st floor was measured. As the door openings increased, airflow and velocity increased. The impact of stair friction on the airflow becomes apparent as the airflow is increased. Significantly large openings are required for friction to affect airflow. The effect of stairwell friction will be negligible with doors closed. 


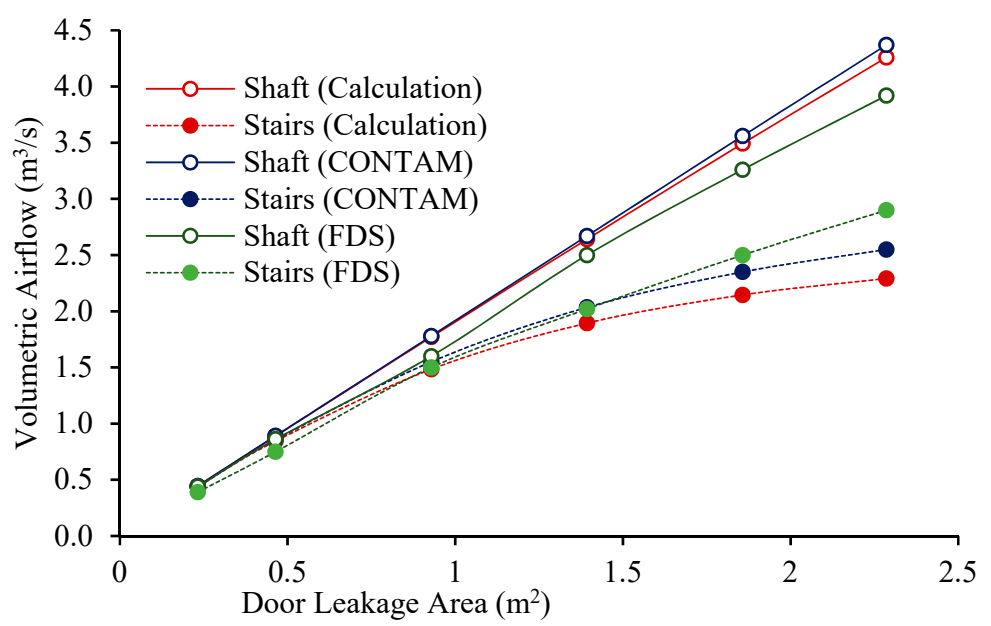

Figure 6. Effect of stairwell friction on airflow at the $1^{\text {st }}$ floor, for a 10 -storey shaft with equally distributed openings.

\subsection{Building Idealization}

To analyze the effect of airtightness on airflow, an idealized model of a MURB was developed (Figure 7). A range of leakage parameters were utilized to capture conditions possible. The building envelope, $A_{1}$, represents the leakage area of the building envelope per floor. The stairwell, $A_{2-1}$ and $A_{2-2}$ represent the leakage area of the stairwell wall and door for each stair shaft per floor. The model does not consider leakage paths through floors as airflow through these paths are proportionally low compared to vertical shafts [15]. Through building idealization, the relevant paths of leakage were defined between each compartment.

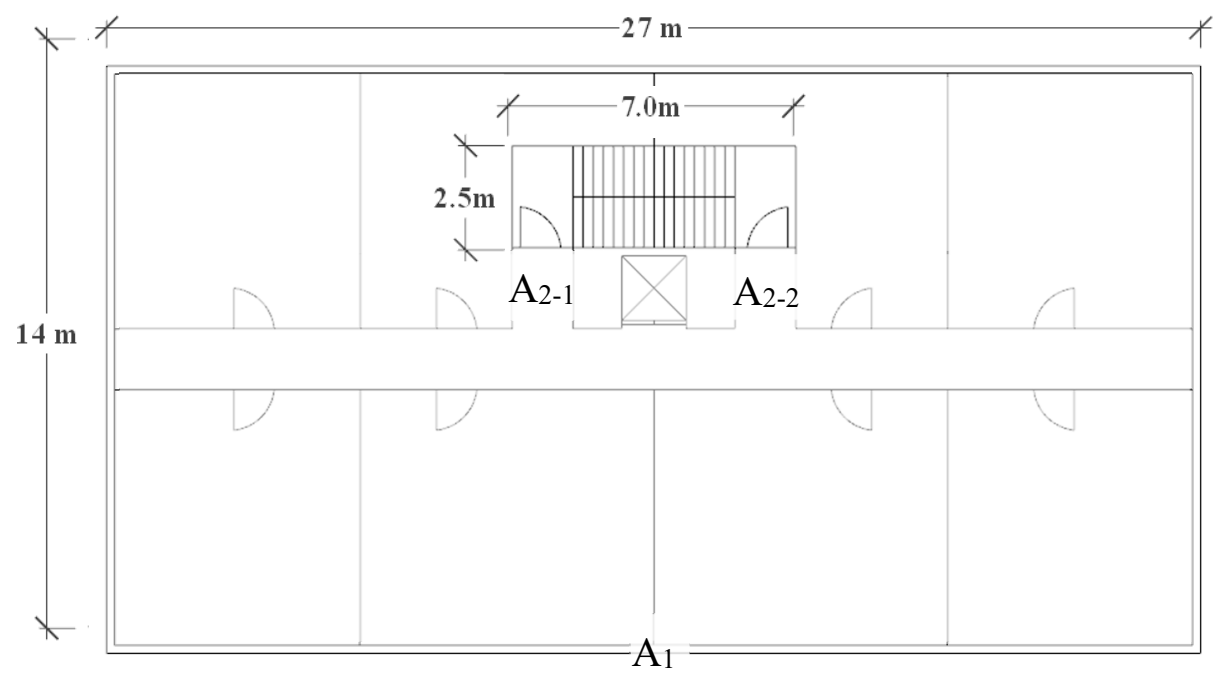

A1- BUILDING ENVELOPE

A2- STAIRWELL WALL AND DOORS

Figure 7. Plan of 10 story MURB used in smoke spread simulation showing idealized paths of leakage.

The outline of corridors and other separators can be seen but are not part of simulations.

Parameters selected for leakage paths $\mathrm{A}_{1}$ and $\mathrm{A}_{2}$ are defined in Table 3. The terms "tight", "average", "leaky", and "very leaky" are used to describe the variable leakage area of exterior walls. The terms "tight", "average", and "leaky" are used to describe the leakage area of stairwells with closed doors. Stairwells with open doors, are described as "open". 
Table 3. Idealized building component parameters.

\begin{tabular}{ccccc}
\hline $\begin{array}{c}\text { Flow Path } \\
\text { ID }\end{array}$ & Flow Path Description & $\begin{array}{c}\text { Normalized } \\
\text { Leakage Area } \\
\left(\mathbf{c m}^{\mathbf{2}} \mathbf{/ \mathbf { m } ^ { 2 } )}\right.\end{array}$ & $\begin{array}{c}\text { Leakage Area per } \\
\text { Floor } \\
\left(\mathbf{m}^{\mathbf{2}} \mathbf{)}\right.\end{array}$ & $\begin{array}{c}\text { Discharge } \\
\text { Coefficient }\left(\boldsymbol{C}_{\boldsymbol{d}}\right)\end{array}$ \\
\hline $\mathrm{A}_{1}$ & Exterior walls (tight) & 1.5 & 0.040 & 0.65 \\
$\mathrm{~A}_{1}$ & Exterior walls (average) & 3.0 & 0.080 & 0.65 \\
$\mathrm{~A}_{1}$ & Exterior walls (leaky) & 6.0 & 0.160 & 0.65 \\
$\mathrm{~A}_{1}$ & Exterior walls (very leaky) & 12.0 & 0.320 & 0.65 \\
$\mathrm{~A}_{2-1}, \mathrm{~A}_{2-2}$ & Stairwell (tight door) & $\mathrm{n} / \mathrm{a}$ & 0.0125 & 0.65 \\
$\mathrm{~A}_{2-1}, \mathrm{~A}_{2-2}$ & Stairwell (average door) & $\mathrm{n} / \mathrm{a}$ & 0.0218 & 0.65 \\
$\mathrm{~A}_{2-1}, \mathrm{~A}_{2-2}$ & Stairwell (leaky door) & $\mathrm{n} / \mathrm{a}$ & 0.0311 & 0.65 \\
$\mathrm{~A}_{2-1}, \mathrm{~A}_{2-2}$ & Stairwell (open door) & $\mathrm{n} / \mathrm{a}$ & 2.0 & 0.35 \\
\hline
\end{tabular}

The effective area of the leakage paths $\mathrm{A}_{1}$ and $\mathrm{A}_{2}$ can be determined using Equations (2) and (3). The leakage area of $A_{2}$ is dependent on the quantity of stairwells and can change the effective area of $A_{1}$ and $A_{2}$. The influence of multiple stairwell shafts can be seen in Figure 8 for a leaky envelope where $A_{1}$ is $0.16 \mathrm{~m}^{2}$. The effective area with a single shaft is much lower than two shafts, assuming doors are closed. As increasing the number of shafts can increase the effective area, this can result in greater airflow. However, the increase in effective area may diminish as more vertical shafts are considered.

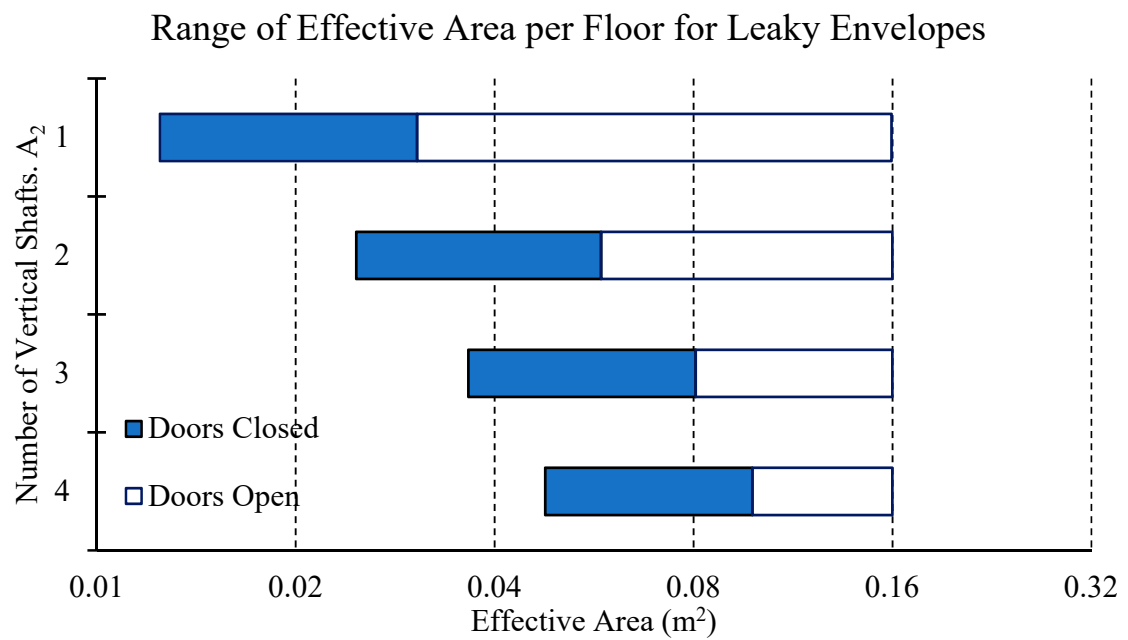

Figure 8. The effective area per floor $\left(\mathrm{A}_{1}\right.$ and $\left.\mathrm{A}_{2}\right)$ is influenced by the number of vertical shafts.

\section{Simulation and Results}

Network and CFD simulations of an idealized 10-storey MURB, described in Figure 7, were conducted to evaluate the effect of airtightness of envelope and stairwell on airflow. The model used a range of parameters determined by experimental data and industry standards. Verification and validation of parameters was individually conducted to compare with mathematical equations and experimental results.

Simulations were conducted with interior air temperature of $20^{\circ} \mathrm{C}$ and ambient air temperature of $-5^{\circ} \mathrm{C}$. Such winter conditions are possible in many cold climate regions, including New York city, where winter design conditions of $-12.6{ }^{\circ} \mathrm{C}$ (dry bulb) annual are recommended [24]. The strength of stack effect will vary depending on the weather conditions which will fluctuate throughout the year and day.

CFD simulations utilized a multi-physics environment that included heat transfer through convection and radiation of surfaces with thermal properties of concrete. Physical obstructions, including the scissor stairwell were modeled. As leakage area for closed doors and building envelope are extremely small, it is not practical to physically model small openings in FDS, as a mesh size would need to be extremely fine [12]. This would make such simulations costly and challenging to conduct. 
Thus, the leakage areas were simulated with surface vents using the HVAC sub-model, which utilize Equation (4). This approach allows for one-way flow only, which is appropriate for the model as temperature and pressure differences are minimal at the top and bottom of the openings [9]. Where air temperature or pressure was influenced by fire, this could have an influence on airflow and necessitate bi-directional flow.

While all leakage areas were modelled using the HVAC sub-model, additional simulations of open-door stairwells were conducted with physical openings, where CFD alone determines the airflow through the orifice. These physical openings allow for bi-directional flow and produced similar results to the HVAC sub-model simulations and are presented in the results.

\subsection{Simulation 1: Evenly Distributed Openings}

An array of 16 simulations were conducted in CONTAM version 3.2. FDS version 6.7.1 was utilized to visualize airflow patterns, the transient environment influence and to compare airflow results for the variation in stairwell $\left(A_{2}\right)$ and envelope $\left(A_{1}\right)$ leakage areas. The simulation results from CONTAM are presented in Table 4 and show the volumetric airflow per floor (measured at $A_{1}$ or $A_{2}$ ) for floors 1 to 10. Positive values, colored in blue, represent airflow entering the stairwell. Negative values, colored in red, represent airflow exiting stairwells. The sum of the airflow describes the total volumetric airflow entering the stairwell, which is equal to the volumetric airflow leaving the stairwell. The relative increase in airflow when the envelope leakage area is increased from "tight" is calculated.

The effective flow area concept demonstrates that the airflow through a series of openings will be restricted by the smallest opening. In most cases, the leakage area of a stairwell $\left(A_{2}\right)$ is proportionally small compared to envelope leakage area $\left(A_{1}\right)$. In such cases, the effective area $\left(A_{e}\right)$ is most influenced by the stairwell or more specifically the leakage areas of stair doors. As the door leakage increases, the effective area increases greatly. For most buildings, airflow due to stack effect is governed by the air-leakage of vertical shaft walls [25].

Simulation results show the significance of the leakage relationship of stairwells and the envelope (Figure 9). The results reveal that tight stairwell doors significantly reduce airflow into stairwells. With tight stairwell doors, little change in airflow occurs as the envelope leakage area increases. A relative increase in airflow of about $15 \%$ can be observed when the building envelope leakage increases to very leaky. In fact, an infinite leakage area of the envelope would not change the airflow much beyond this value as the stairwell door is the restrictive opening.

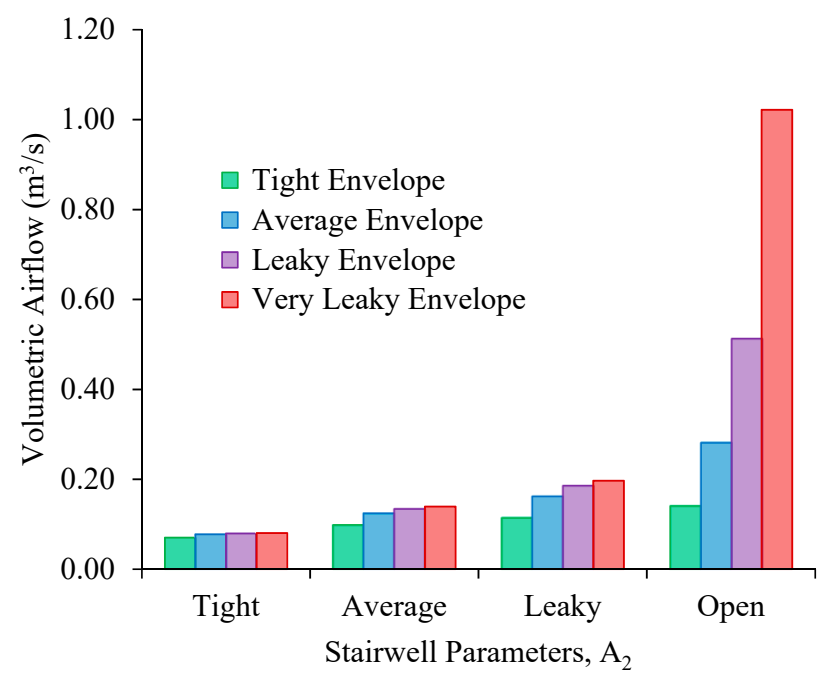

Figure 9. Airflow into the 1st floor stairwell for tight, average, and leaky envelopes. 
Table 4. Volumetric airflow into stairwells for variations in building envelope and stairwell airtightness.

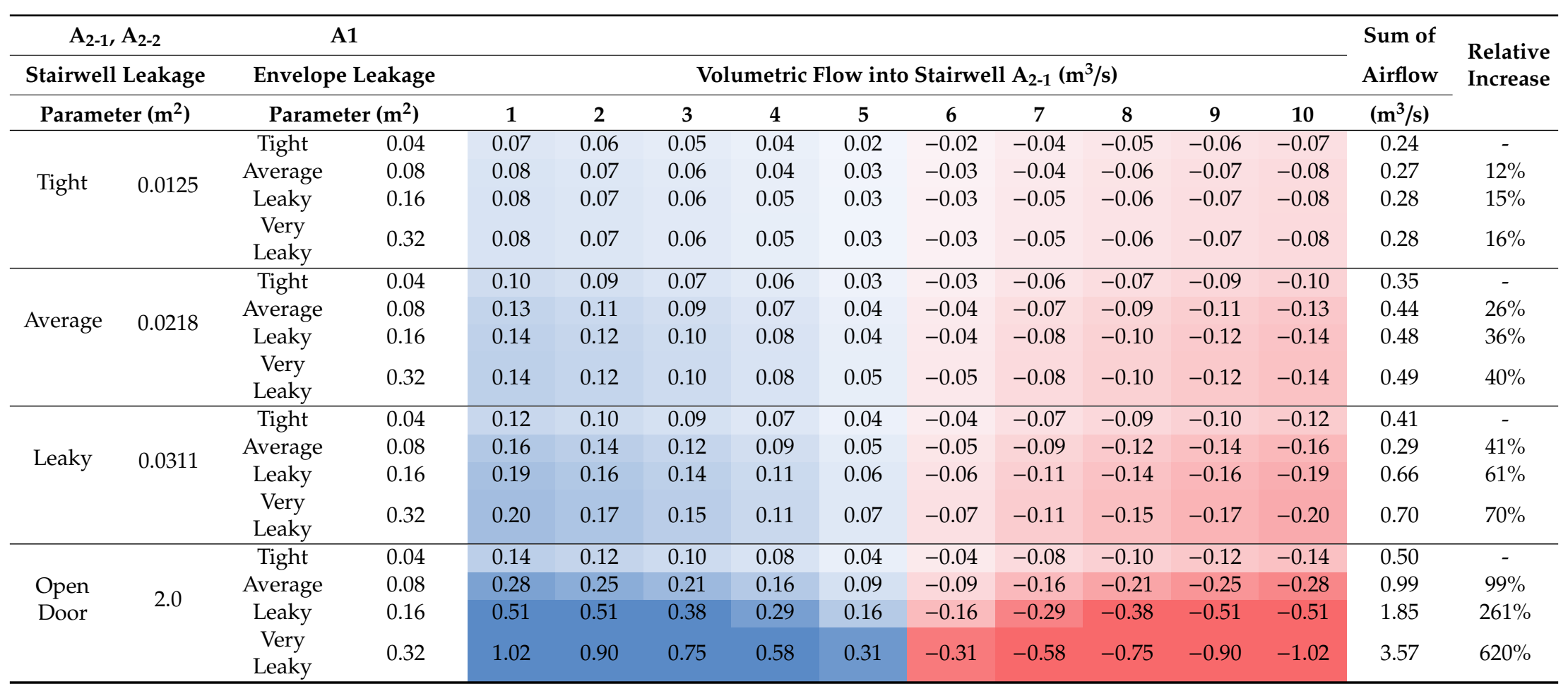


As the stairwell door leakage area increases, more airflow results. Leaky stairwell doors allow vastly greater airflow as the building envelope leakage increases. Simulations of leaky stairwell doors revealed a $70 \%$ increase in volumetric flow for a very leaky envelope. However, as the leakage area of the stairwell approaches that of the building envelope, the envelope begins to restrict airflow.

For stairwells with open doors, the leakage area due to open doors is significantly larger than that of the building envelope. With stairwell doors open, the effective area is most restricted by the envelope leakage area. Thus, the tightness of the envelope is responsible for limiting airflow into stairwells. The maximum volumetric flow through an open stairwell door was $0.14 \mathrm{~m}^{3} / \mathrm{s}$ for a tight envelope and $1.02 \mathrm{~m}^{3} / \mathrm{s}$ for a very leaky envelope. This represents an increase of $620 \%$.

The increased airflow in stairwells result in the spread of air and potential contaminants throughout buildings. As existing buildings vary in airtightness, variations in the quantity of airflow entering stairwells can be expected. Experiments have demonstrated older buildings to have leakier envelopes [5]. Assuming stairwells are also leakier, the airflow into stairwells can be expected to be higher. Older buildings with both leaky envelopes and doors may be subject to increased airflow. The increased airflow in stairwells can result in the spread of air and potential contaminants throughout the building. Buildings with tight stairwell doors can be expected to minimize airflow into stairwells. This may prove effective for buildings with tight and leaky envelopes.

The FDS simulations were conducted for a duration of $120 \mathrm{~s}$ and were subject to transient effects, such as the influx of ambient air and heat exchange between model surfaces. CONTAM simulations by contrast were steady state and produce constant results. The comparison of the results can be seen in measurements of airflow at stairwell doors. The simulations produced very agreeable results for both low and high airflow measurements, as can be seen in Figures 10 and 11. For clarity, CONTAM results are shown for 0 to $60 \mathrm{~s}$.

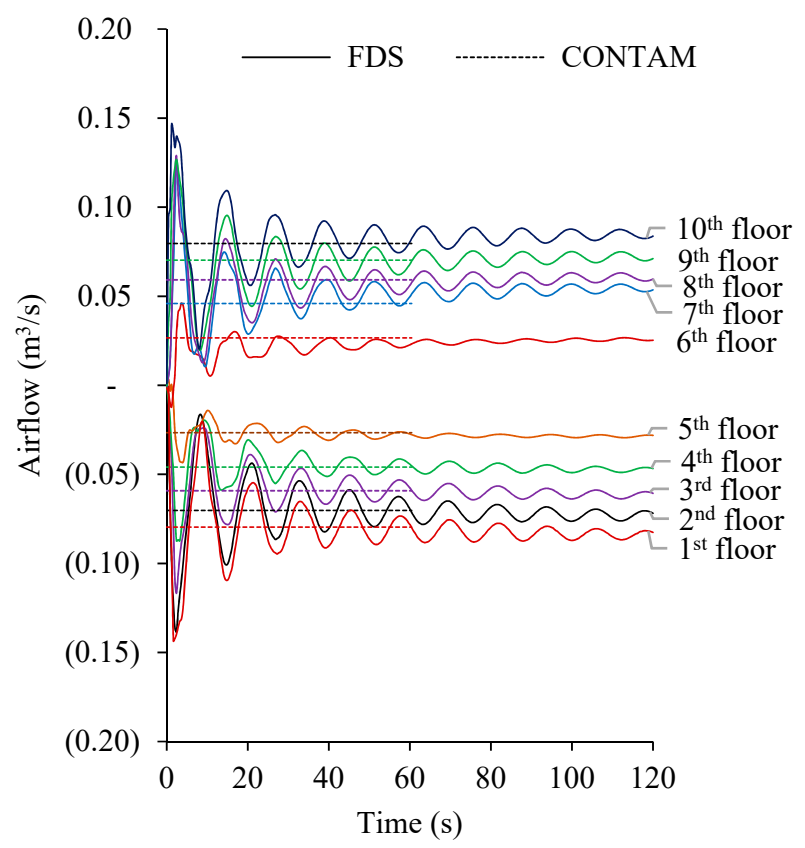

Figure 10. CONTAM and Fire Dynamics Simulator (FDS) results for airflow at vertical shafts, simulation: tight stairwell and leaky envelope.

Simulations with stairwells doors closed resulted in low airflow velocity (Figure 12). In FDS, leakier envelopes allowed noticeable infiltration of exterior air. This cooler air sinks when entering the stairwell at low velocity, demonstrating laminar flow. With open doors, higher airflow velocity results and turbulence and mixing occurs in stairwells. The turbulence is apparent when velocity is measured at the door vents, $\mathrm{A}_{2}$ (Figure 13). Simulations with open doors modelled using vents and physical 
openings resulted in similar airflow patterns. The results were nearly identical when compared to the vent method, if measured in at $\mathrm{A}_{1}$ (Figure 14).

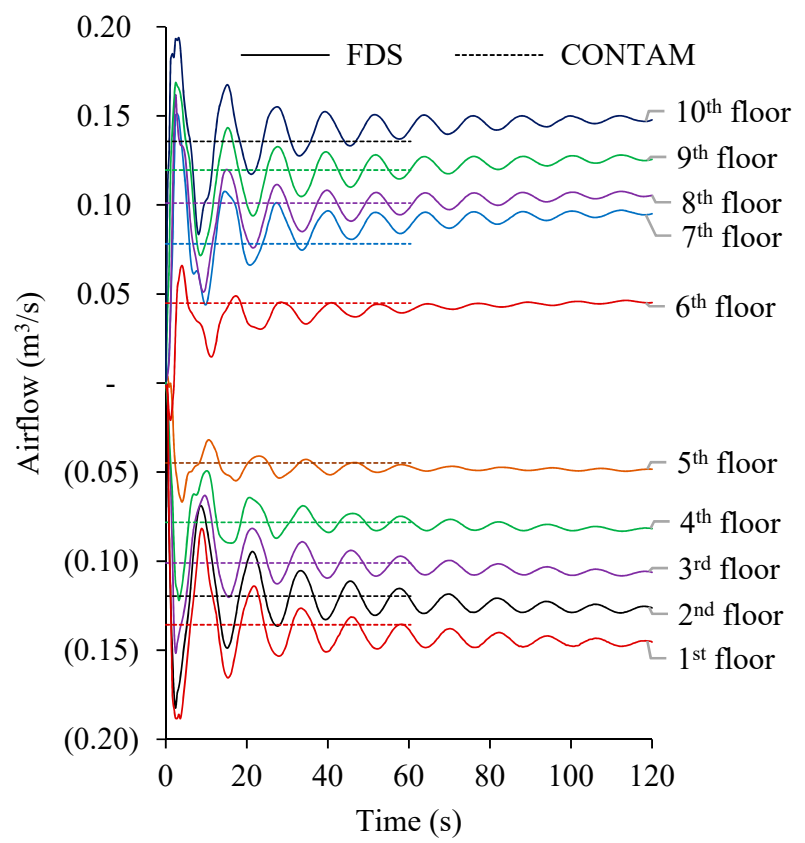

Figure 11. CONTAM and FDS results for airflow at vertical shafts, simulation: average stairwell and leaky envelope.

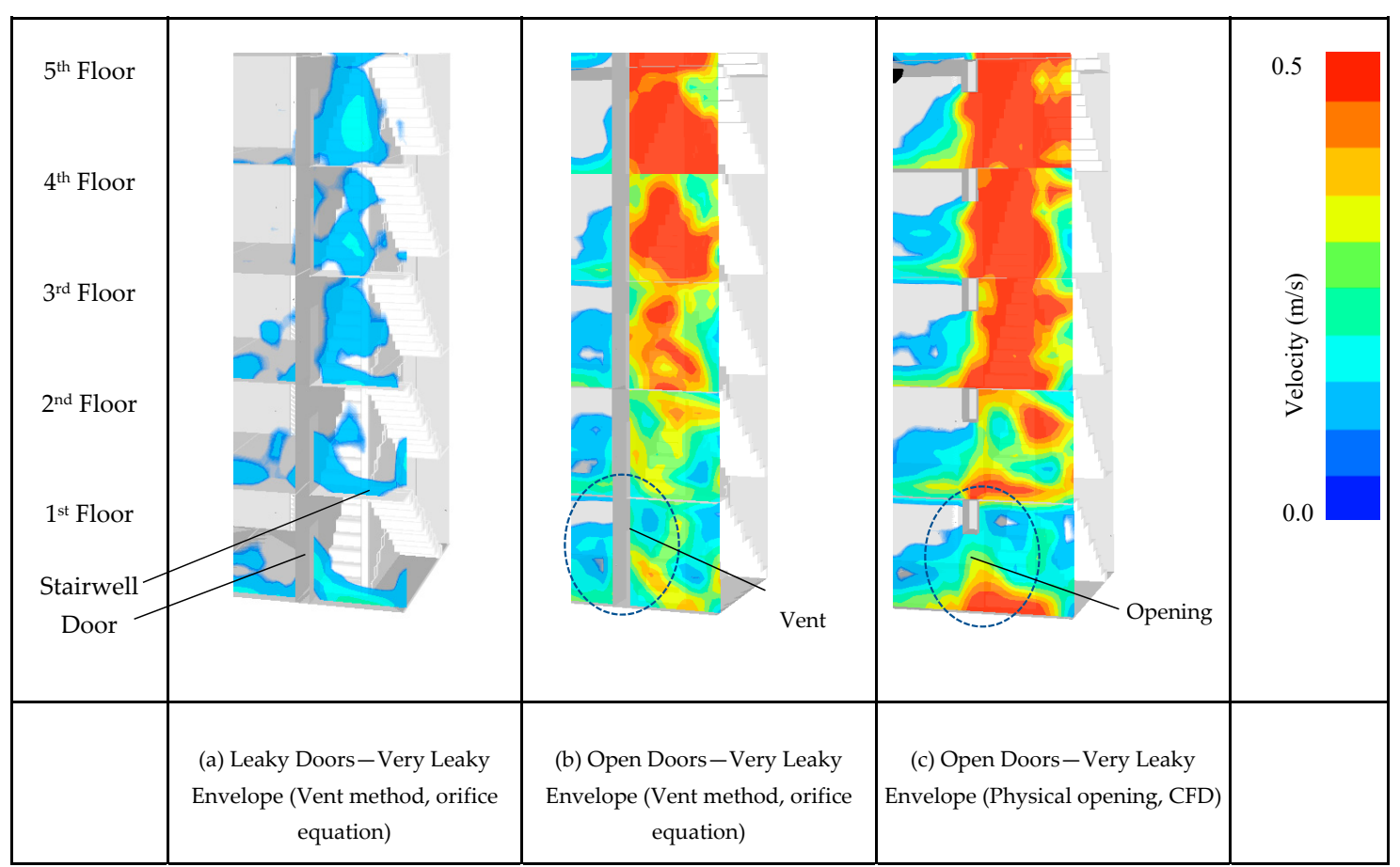

Figure 12. Airflow velocity along vertical plane for floors 1 to 5 , for (a) leaky doors $(\mathbf{b}, \mathbf{c})$ open doors. 


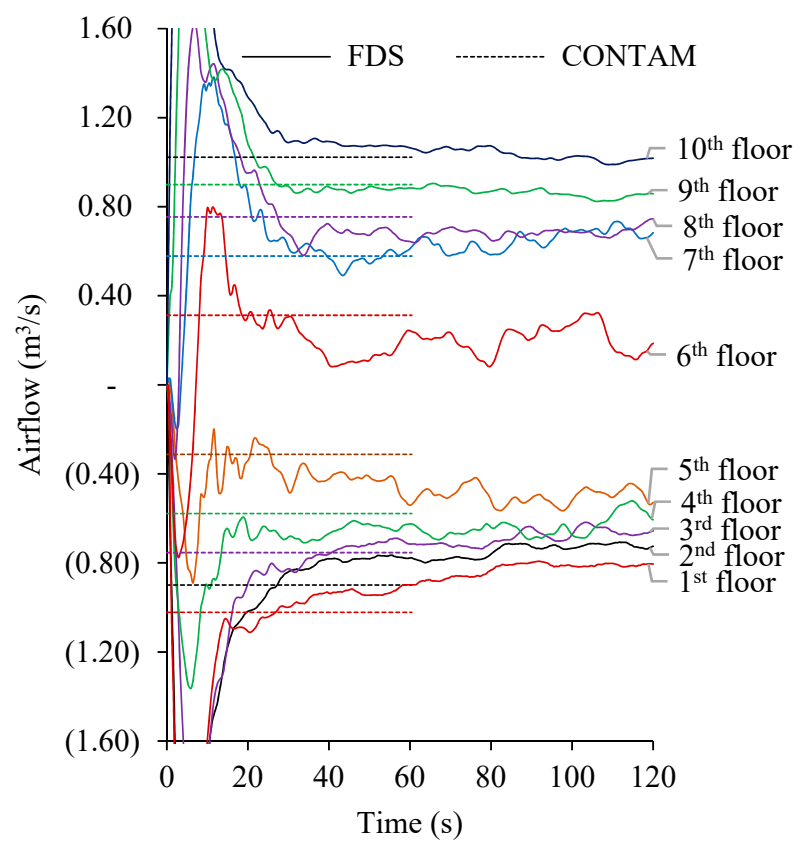

Figure 13. Airflow with open stair doors and very leaky envelope, measured at $A_{2}$ utilizing the vent method.

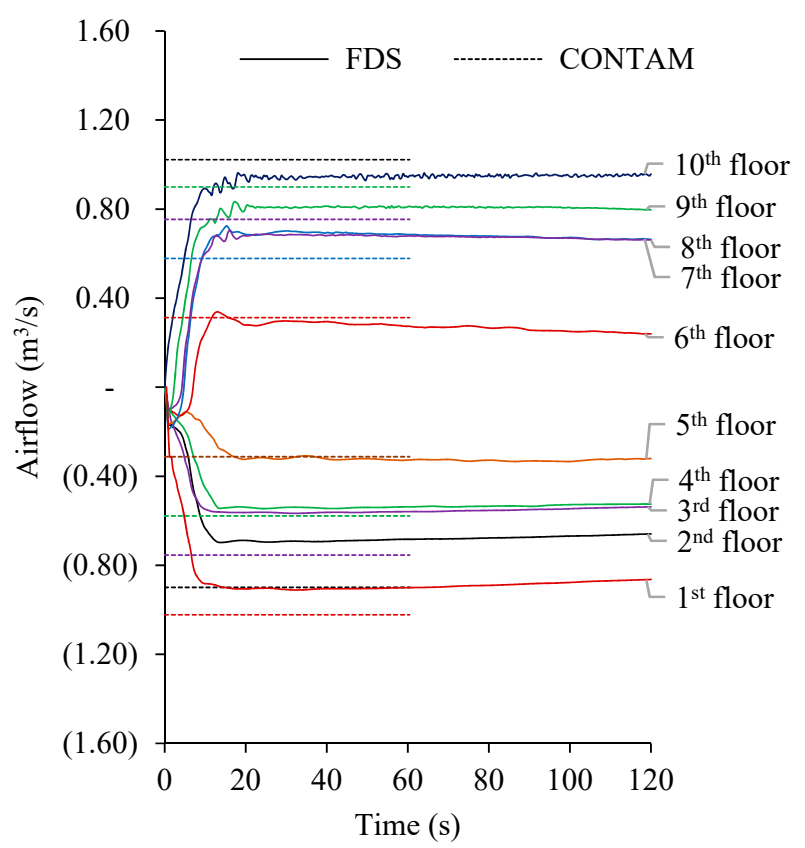

Figure 14. Airflow simulation of open stair doors and a very leaky envelope measured at $A_{1}$ utilizing the physical opening method.

Simulations with stairwell doors closed resulted in low airflow velocity (Figure 12). In FDS, leakier envelopes allowed noticeable infiltration of exterior air. This cooler air sinks when entering the stairwell at low velocity, demonstrating laminar flow. With open doors, higher airflow velocity results and turbulence and mixing occurs in stairwells. The turbulence is apparent when velocity is measured at the door vents, $\mathrm{A}_{2}$ (Figure 13). Simulations conducted with modelled door openings resulted in similar airflow patterns. The results were nearly identical when compared to the vent method, if measured in the at $\mathrm{A}_{1}$ (Figure 14). 


\subsection{Simulation 2: Top and Bottom Openings in Building Envelope}

When the leakage openings are evenly distributed, the NPP occurs at the buildings mid-height. Even distribution of openings does not often occur in actual buildings, as larger openings may exist due to open lobbies, doors, variation in envelope tightness or geometry. The effect of uneven openings can have a large impact, particularly when large openings exist toward the top or bottom of the building. The airflow resulting from an open door can change the stack pressure profile within a building.

Simulations were conducted to evaluate the effect of top and bottom openings on airflow. The simulations were conducted using the very leaky envelope $\left(0.32 \mathrm{~m}^{2}\right)$ and leaky door $\left(0.0311 \mathrm{~m}^{2}\right)$ parameters used in Simulation 1. Further modifications were made as described below. For bottom openings, simulations utilized the following additional parameters:

- $\quad$ an orifice of $4 \mathrm{~m}^{2}$ in the building envelope $\mathrm{A}_{1}$ was specified at the 1 st floor.

- $\quad$ open stairwell doors of $2 \mathrm{~m}^{2}$ for $\mathrm{A}_{2-1}$ and $\mathrm{A}_{2-2}$ were specified at the 1 st floor.

For top openings, simulations utilized the following additional parameters:

- $\quad$ an orifice of $4 \mathrm{~m}^{2}$ in the building envelope $\mathrm{A}_{1}$ was specified at the 10 th floor.

- open stairwell doors of $2 \mathrm{~m}^{2}$ for $\mathrm{A}_{2-1}$ and $\mathrm{A}_{2-2}$ were specified at the 10th floor.

The results of the simulation are seen in Table 5 , and can be compared to the previously simulated very leaky envelope and leaky door simulation.

With a bottom opening, airflow of $1.82 \mathrm{~m}^{3} / \mathrm{s}$ is observed to enter the stairwell on the $1^{\text {st }}$ floor (Table 5). Air moves from stairwell to corridors on the 2nd floor and above, indicating the NPP is located within the $2^{\text {nd }}$ floor. Simulations in FDS show the stack pressure in the stairwell increases (Figure 15) and high airflow velocities occur (Figure 16). With a top opening, airflow of $1.82 \mathrm{~m}^{3} / \mathrm{s}$ is observed to exit the stairwell on the $10^{\text {th }}$ floor (Table 5). Air moves from the corridors to the stairwell on the $9^{\text {th }}$ floor and below (Table 5). A top opening reduces stack pressure in the stairwell as seen in Figure 15. Both scenarios change NPP location and airflow patterns within the building.

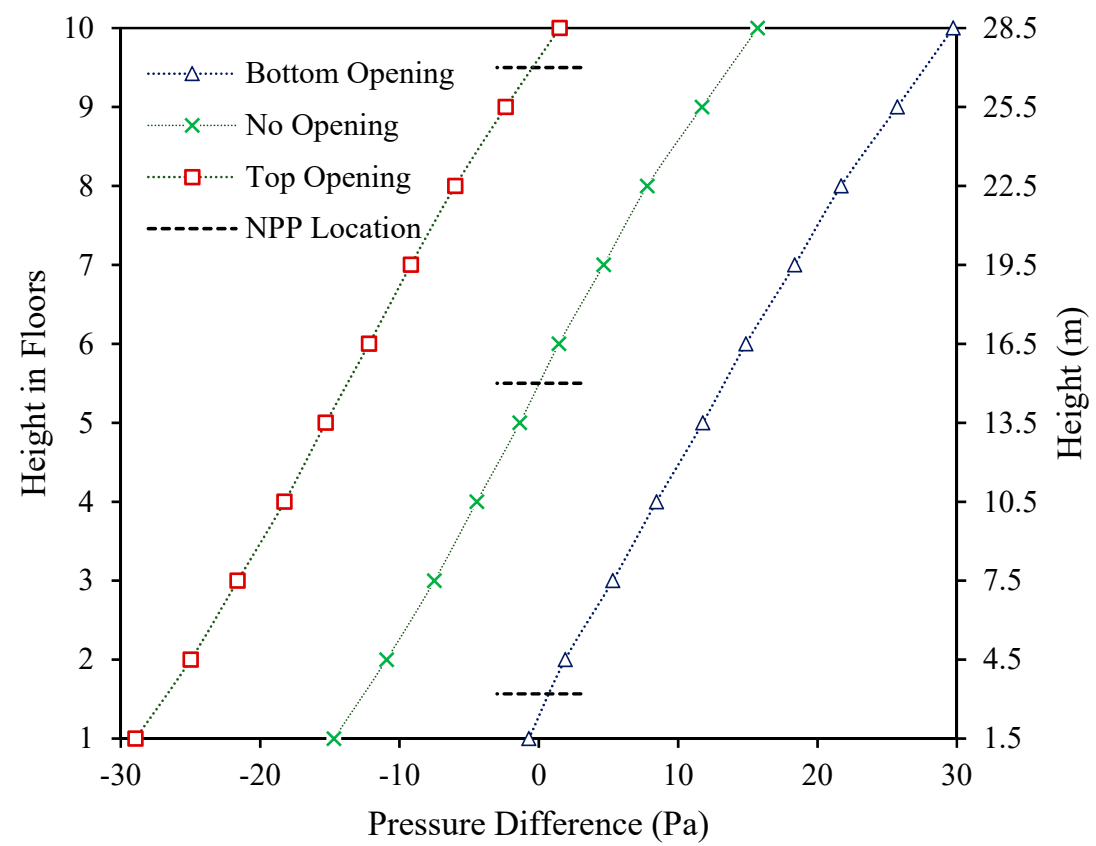

Figure 15. Stairwell stack pressure for average envelope and leaky closed door simulations with openings measured in FDS at mid-floor height. 
Table 5. Airflow through stairwell doors for Open Bottom and Open Top conditions.

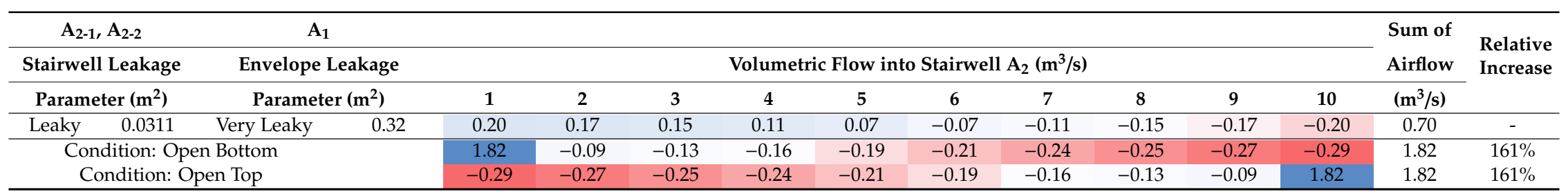




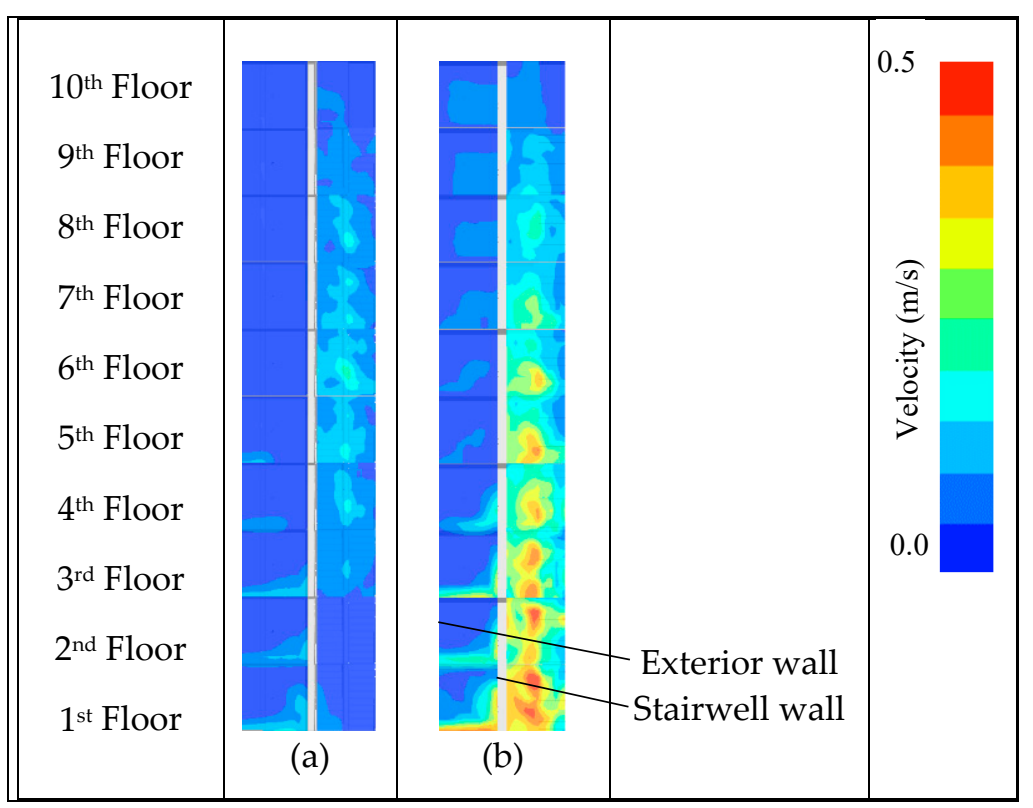

Figure 16. Cross-section of building showing airflow velocity entering stairwell for simulations with (a) evenly distributed openings and (b) bottom opening.

Steady state simulations in CONTAM produced agreeable results to transient simulations in FDS. However, when large openings are present, the influx of cold outside air entering the stairwell will reduce stack pressure over time. Simulations in FDS show a change in airflow over time as stack pressure is reduced with a bottom opening (Figure 17). For a top opening, stack pressure does not change significantly as air entering the stairwell is from the building (Figure 18). The decrease in stack pressure due to the influx of outdoor air is dependent on the building properties including the volume of compartments which can dilute outdoor air, heat transfer from building surfaces, and HVAC systems. Sustained influx of large quantities of cold outdoor air will affect the airflow over time.

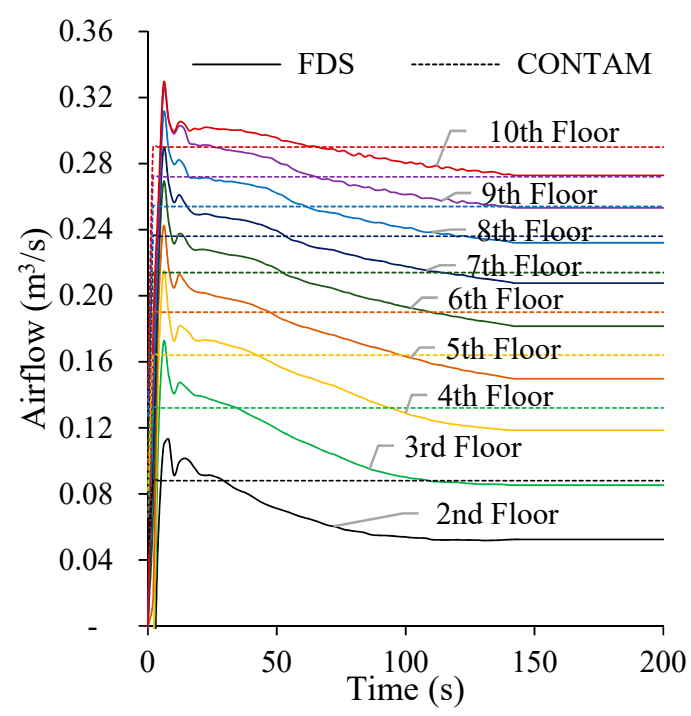

Figure 17. Airflow through stairwell doors for $1^{\text {st }}$ floor openings in FDS and CONTAM. 


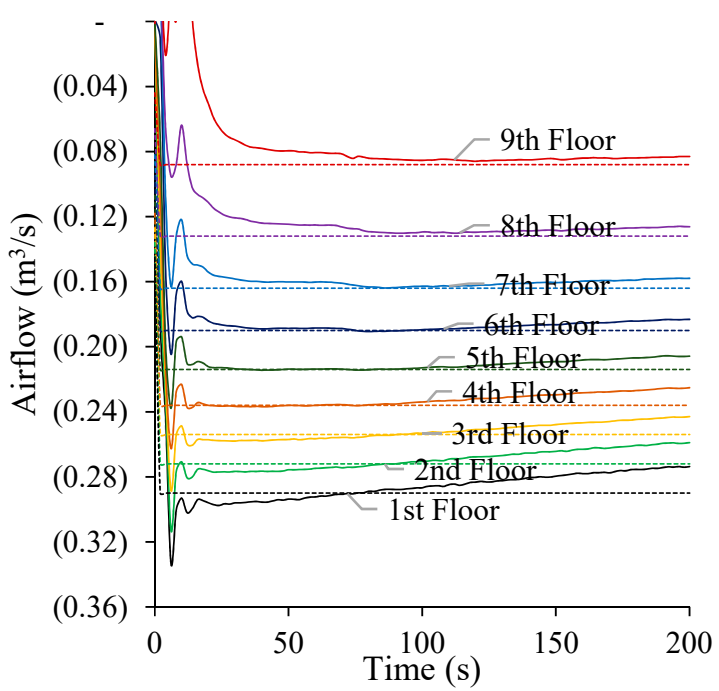

Figure 18. Airflow through stairwell doors for $10^{\text {th }}$ floor openings in FDS and CONTAM.

Increased airflow into the stairwell is often seen as a negative effect on maintaining smoke free egress. However, this may depend on the fire scenario and the origin of the fire. For instance, airflow from stairwells into corridors may prevent smoke spread into stairwells. A bottom opening can be created during egress when entrance doors are propped open. The pressurization caused by the bottom opening could improve tenability time. The top opening results in air entering the stairwells at an increased rate for all floors. This would be problematic in all fire scenarios, except when the fire is located on the top floor.

\subsection{Simulation 3: Select Door Openings}

Simulations were conducted with select doors open to evaluate the airflow created under scenarios where a select few stairwell doors may be left open. The simulations were conducted very leaky envelope $\left(0.32 \mathrm{~m}^{2}\right)$ and leaky door $\left(0.0311 \mathrm{~m}^{2}\right)$ parameters used in Simulation 1. Each simulation utilized these parameters in addition to open stairwell doors on the:

- 1st floor;

- 1 st and 10th floor;

- 1 st, 3rd, 5th, 7th, and 9th floor.

Table 6 shows the results of door openings with comparison to "all doors closed" and "all doors open". Select stairwell door openings affected the airflow into stairwells. Open 1st floor stairwell doors resulted in airflow of $0.83 \mathrm{~m}^{3} / \mathrm{s}$ entering through each stairwell door $\left(\mathrm{A}_{1}\right)$ on the 1 st floor. Open 1 st and 10th floor stairwell doors resulted in $1.02 \mathrm{~m}^{3} / \mathrm{s}$ entering the 1 st floor stairwell doors $\left(\mathrm{A}_{1}\right)$. Numerous stairwell door openings on multiple floors resulted in $0.98 \mathrm{~m}^{3} / \mathrm{s}$.

In general, the total airflow entering the stairwells is increased with the number of doors open. The airflow entering the stairwell ranges between $0.7 \mathrm{~m}^{3} / \mathrm{s}$ for "all doors closed" and $3.57 \mathrm{~m}^{3} / \mathrm{s}$ for "all doors open" simulations. The opening of doors nearest the top or bottom have the largest influence on airflow. By opening top and bottom doors, an increase in airflow of $116 \%$ is observed. Open doors near the NPP experienced low airflow. Figure 19 shows the airflow through stairwell doors on the 1st floor for select door simulations in FDS. 
Table 6. Airflow into stairwells for conditions with stairwell doors open.

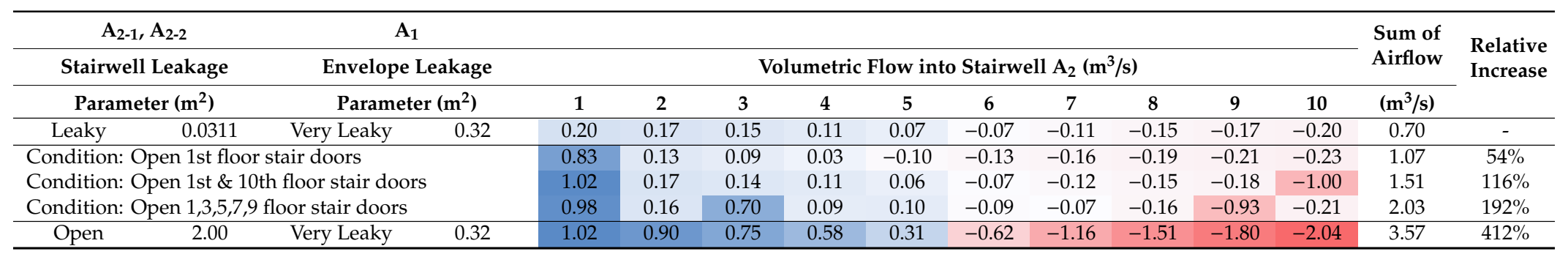




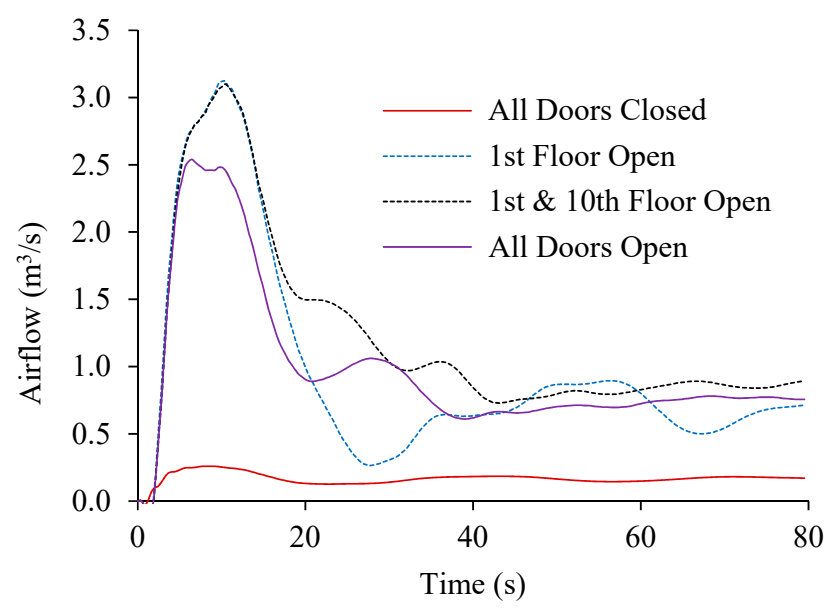

Figure 19. Stairwell door openings effect on airflow into the 1st floor stairwell $\left(A_{2}\right)$ for very leaky envelopes.

A detailed look at the effect of opening the 1st floor door shows a large increase in airflow entering the stairwell. The entering air increases pressure within the shaft and results in lowering the NPP to the 4th floor. Airflow entering the stairwell is reduced below the NPP and increased above it. Opening the bottom stairwell doors results in increased spread of air from the 1st floor to those floors above the NPP. Contamination of air on the first floor would result in its distribution at a faster rate.

For many buildings, several contamination sources exist near the 1st floor. Traffic and exhaust of nearby vehicles entering the 1st floor would be spread faster to upper floors. The presence of contamination on the 2nd floor would have benefit from the opening of the 1st floor. Reduced airflow into the stairwell would reduce the rate of migration throughout the building. The hazard poised by stack driven airflow will depend on the location of contamination and occupied areas.

\section{Discussion}

Airflow within buildings is a result of the leakage paths and imposed pressure differentials. Variation in building leakage characteristics can affect the magnitude of airflow and patterns, as demonstrated in Simulations 1-3. A tight building is fundamental to reducing uncontrolled air movement throughout the building. The stack driven airflow has consequences that extend to multiple disciplines of building design and engineering. The influence can be noted on IAQ and smoke spread, energy efficiency and thermal comfort, and even building envelope performance. While envelope retrofits may improve the airtightness, leakage paths in stairwells and vertical shafts may be easily addressed. For example, improving airtightness of stairwell doors can be easily addressed by the use of gaskets. Ensuring doors to stairwells remain closed reduces the potential for significant airflow.

\subsection{Envelope}

Minimizing airflow through building envelopes is desirable as the migration of moisture laden air between interior and exterior is reduced. Depending on the leakage path, the accumulation of moisture from condensation can result. Where leakage paths are within predominantly inert metal and glass enclosures, the degradation potential is minimal. However, where leakage paths occur in building enclosures such as masonry, concrete, and drywall, moisture can accumulate, degrade insulation, corrode metal components and lead to mould growth.

Within heating climates, building envelope damage is often observed at the upper floors of a building [26]. Moisture laden air from the interior is exfiltrated through the envelope and results in interstitial condensation. Reducing airflow through the building envelope can decrease potential problems with building envelope systems. Envelope retrofits are often done to limit the airflow through 
exterior walls. Buildings with airflow due to stack effect may be able to reduce the migration of moist air through exterior envelopes by increasing airtightness of stairwells and vertical shafts.

\subsection{IAQ and Spread of Contaminants}

The movement of contaminants within MURB's is difficult to control. Contaminants from one space can easily migrate to another space when stack effect and leakage paths exist. Under stack pressure, the leakage areas of building envelope and vertical shafts will affect the rate of airflow within the building. Larger leakage areas will result in higher rates of airflow and could result in contaminants being spread faster from floor to floor.

The movement of contaminants will depend on their origin, the airflow pattern, and NPP location. The spread of smoke from a corridor to stairwell could be accelerated with increased airflow due to stack effect. Leakier conditions will result in increased smoke entering the stairwells and eventually entering corridors and suites. This can affect the available safe egress time (ASET) and thus leakier buildings may be more susceptible to spread of contaminants.

Supply ventilation reduces concentrations of indoor generated pollutants to some degree [27]. HVAC supply air generally receives filtration and conditioning and is the desired source of ventilation. In many existing MURBs in Canada, MAU supply the corridor with fresh air. Stack effect during winter can cause suites on lower floors to receive reduced supply air as airflow into vertical shafts prevail. ASHRAE 62.1-2016 now recommend a supply of fresh to suites directly based on occupants or floor area for various assemblies. Considering the supply of $0.3 \mathrm{~L} / \mathrm{s} / \mathrm{m}^{2}$, for the idealized model floor area of $408 \mathrm{~m}^{2}$, roughly $122 \mathrm{~L} / \mathrm{s}$ of supply air would be divided between suites per floor.

$\mathrm{RDH}$ Building Engineering Ltd. testing of airflow found that significant quantities of supply air in corridors was not reaching the suites for which it was intended [8]. For corridor supplied air intended for suites, only $20 \%$ reached suites and a large proportion able to enter vertical shafts: $29 \%$ stairwell doors, $41 \%$ elevator doors. Attributed partially to stack effect, suites on lower floors received approximately 5 to $13 \mathrm{~L} / \mathrm{s}$, significantly less than what may be required from ASHRAE 62.1 IAQ standards. Suites on upper floors received upwards of $70 \mathrm{~L} / \mathrm{s}$. This demonstrates that design specifications, when subject to environmental conditions, may fail to meet intended results.

In such a situation, the mechanical systems could be balanced to provide increased supply air at lower floors during cooler ambient temperatures. However, reducing the leakage into vertical shafts, particularly on lower floors may be a worthwhile measure. The problem associated with airflow through vertical shafts can be made clear when considering HVAC supply air within the context of the idealized MURB model.

Considering the 10-storey MURB model used in simulations, and the need to supply $200 \mathrm{~L} / \mathrm{s}$ of fresh air to corridors, the amount delivered to suites will vary depending on the leakage characteristics. For instance, the airflow into the stairwell from the 1st floor for Simulation 1, "leaky" stairwell and "very leaky" envelope, indicates an airflow of $0.20 \mathrm{~m}^{3} / \mathrm{s}(200 \mathrm{~L} / \mathrm{s})$. Thus, the supply air would be ineffective at providing fresh air to suites on the first floor. However, decreasing the air leakage of only the stairwell to "tight", perhaps by using gaskets at doorframes or sealing of penetrations, could reduce airflow entering the stairwells to $0.08 \mathrm{~m}^{3} / \mathrm{s}(80 \mathrm{~L} / \mathrm{s})$.

\subsection{Energy and Thermal Comfort}

The infiltration of outdoor air also increases energy consumption of HVAC systems. While the method of ventilation may vary, many existing MURBs in Canada utilize MAU to pressurize corridors. A study of 39 mid to high-rise MURB in Canada found MAU utilize an estimated $69 \%$ of total space heating energy [28]. Considering the 10-storey MURB model used in simulations, the supply of $200 \mathrm{~L} / \mathrm{s}$ of fresh air to corridors would equate to $2000 \mathrm{~L} / \mathrm{s}$ for the entire building. The net airflow, from Table 4, demonstrates that "tight" stairwells range from $0.247 \mathrm{~m}^{3} / \mathrm{s}(247 \mathrm{~L} / \mathrm{s})$ to $0.284 \mathrm{~m}^{3} / \mathrm{s}(284 \mathrm{~L} / \mathrm{s})$. Thus, airflow from stack effect is between $10 \%$ to $15 \%$ in simulated conditions. However, open stairwell doors could allow for between $0.5 \mathrm{~m}^{3} / \mathrm{s}(500 \mathrm{~L} / \mathrm{s})$ and $3.57 \mathrm{~m}^{3} / \mathrm{s}(3570 \mathrm{~L} / \mathrm{s})$, which would represent half 
to twice the amount of supply air. Obviously, this would result in poor performance of HVAC and higher cost for heating and cooling.

Infiltration driven by stack effect will be most prominent on the lowest and highest floors. Energy efficiency and thermal comfort may be severely affected in leaky envelopes at these locations. Space heating of suites on the lower floors will have proportionately higher energy demands. If airflow rates are high enough, they may overwhelm the heating system and result in issues surrounding thermal comfort.

\subsection{Limitations}

Simulations performed in this study evaluated relevant paths of leakage present in MURB buildings. The idealized model simplifies conditions of buildings to facilitate analysis and comparison of results. The simulations performed estimated airflow driven by stack effect only. Environmental conditions such as wind were not included within simulations. Mechanical HVAC supply and exhaust, pressurization of corridors, were not included the simulations.

The idealized conditions do not exclusively consider the effect of interior partitions, such as those created by corridors. A great challenge in simulating building airflow is the wide variety of airtightness and compartmentation seen in buildings. Additional variables of operable windows and doors can change the actual airtightness since these openings may be larger than the leakage area of the envelope [6]. Due to this, a range of building leakage parameters are utilized to account for a spectrum of building conditions.

The idealized model contains a vertical shaft consisting of a scissor stair. It should be noted, that the addition of vertical shafts will alter the airflow characteristics entering through stairwell doors. Increasing the number of vertical shafts will increase the effective area and airflow through the building. The airflow into vertical shafts will be divided amongst the number of shafts. Additionally, other vertical shafts, including vents and elevators, will have different leakage characteristics and will also influence airflow results.

\subsection{CFD Environment}

CFD simulations were performed in FDS representing the environment boundaries with open vents, producing ambient conditions that exist beyond the modeled confines. The MURB geometry illustrated in FDS included a scissor stairwell, servicing all 10 floors. The interior was specified with an initial temperature of $20^{\circ} \mathrm{C}$. To represent leakage paths at the envelope, closed and open stairwell doors, one-way vents were specified. Open doors were also modeled as physical openings, producing similar results as described in Figure 14. The simulations used a mesh size of $20 \mathrm{~cm}$ and were run for a duration of $200 \mathrm{~s}$.

\section{Conclusions}

Stack driven airflow has consequences on IAQ and smoke spread, energy efficiency, and thermal comfort. The benefit of reducing leakage in buildings can be understood by comparing the quantity and patterns in airflow. The trend towards taller and larger structures emphasizes the importance of analysis of airflow due to stack effect in early design stages [27].

Parametric analysis of the 10-storey MURB evaluated a range of envelope and stairwell leakage parameters on airflow. Simulations using network modeling in CONTAM and CFD in FDS measured airflow in and out of stairwells due to stack pressure, with ambient temperatures of $-5^{\circ} \mathrm{C}$. Through these simulations, the effect of leakage characteristics and open stairwell doors can be measured.

The relationship between envelope and stairwell leakage area can influence the airflow. The effective flow area concept helps illustrate that airflow will be most restricted by the smallest opening in a series. Thus, tight vertical shafts can limit the consequence of leaky envelopes and vice versa. A tight envelope with leaky vertical shafts will restrict the amount of airflow entering the building. However, if the envelope leakage area is increased, the airflow into stairwells will be amplified. 
Experiments have demonstrated older buildings to have leakier envelopes [7]. Older buildings with both leaky envelopes and doors may be subject to increased airflow. The increased airflow in stairwells can result in the spread of air and potential contaminants throughout the building. By contrast, buildings with tight envelopes and stairwells significantly reduce airflow and benefit from reduced hazards and energy loss.

Author Contributions: Z.L. and P.M. conceived and designed the experiments; P.M. performed the experiments; Z.L. and P.M. analyzed the data and wrote the paper.

Funding: This work is partially funded by Natural Sciences and Engineering Research Council of Canada, discovery Grant (NSERC DG, CPI\#1130083) and Hubei Chutian Scholars Program, China.

Conflicts of Interest: The authors declare no conflict of interest.

\section{References}

1. Tamura, G.T. Computer Analysis of Smoke Movement in Tall Buildings; National Research Council: Ottawa, ON, Canada, 1969.

2. Tamura, G.T.; Shaw, C.Y. Studies on exterior wall air tightness and air infiltration of tall buildings. ASHRAE Trans. 1976, 82, 122-134.

3. Tamura, G.T.; Achakji, G.Y. Pressure drop characteristics of typical stairshafts in high-rise buildings. ASHRAE Trans. 1998, 94, 1223-1237.

4. Gross, D.; Haberman, W.L. Analysis and Prediction of Air Leakage Through Door Assemblies. In Proceedings of the 2nd International Symposium on Fire Safety Science, Tokyo, Japan, 13-17 June 1988.

5. Gulay, B.W.; Stewart, C.; Foley, G.J. Field Investigation Survey of Airtightness, Air Movement and Indoor Air Quality in High Rise Apartment Buildings Summary Report; Canada Mortgage and Housing Corporation: Winnipeg, MB, Canada, 1993.

6. RDH Building Engineering Ltd. Air Leakage Control in Multi-Unit Residential Buildings; RDH Building Engineering Ltd.: Vancouver, BC, Canada, 2013.

7. Lay, S. Pressurization systems do not work \& present a risk. Case Stud. Fire Saf. 2014, 1, 13-17.

8. Rickets, L. A Field Study of Airflow in a High-Rise Multi-Unit Residential Building; University of Waterloo: Waterloo, ON, Canada, 2014.

9. Dols, W.S.; Polidoro, B.J. Contam User Guide and Program Documentation Version 3.2; NIST Technical Note 1887; National Institute for Standards and Technology: Gaithersburg, MD, USA, 2015.

10. Walton, W.D.; Carpenter, D.J.; Wood, C.B. Zone Computer Fire Models for Enclosures. In SFPE Handbook of Fire Protection Engineering; Society of Fire Protection Engineers: Bethesda, MD, USA, 2016; pp. 1024-1033.

11. McGrattan, K.; Stewart, D.M. Modeling Fires Using Computational. In SFPE Handbook of Fire Protection Engineering; Society of Fire Protection Engineers: Bethesda, MD, USA, 2016; pp. 1034-1065.

12. McGrattan, K.; Hostikka, S.; McDermott, R.; Floyd, J.; Weinschenk, C.; Overholt, K. Fire Dynamics Simulator (Version 5) User's Guide; NIST Special Publication: Gaithersburg, MD, USA, 2015; Volume 1019.

13. Ricketts, L.; Finch, G.; Straube, J. Pressure Differences and Airtightness in Tall Buildings-Theory \& Reality. In Proceedings of the Fourth NIBS Building Enclosure Science Technology Conference, Kansas City, MO, USA, 13-15 April 2015.

14. Tanaka, T. Vent Flows. In The SFPE Handbook of Fire Protection Engineering, 5th ed.; National Fire Protection Association: Quincy, MA, USA, 2016; pp. 455-485.

15. Klote, J.H.; JMilke, A. Principles of Smoke Management; American Society of Heating, Refrigerating and Air-Conditioning Engineers, Inc.: Atlanta, GA, USA, 2002.

16. Klote, J.H. Considerations of Stack Effect in Building Fires; National Institute of Standards and Technology: Gaithersburg, MD, USA, 1989.

17. Hutcheon, N.B.; Handegord, G.O. Building Science for a Cold Climate; Institute for Research in Construction: Ottawa, ON, Canada, 1995.

18. Straube, J.F.; Burnett, E.F. Building Science for Building Enclosures; Building Science Press: Westford, MA, USA, 2005.

19. Tamura, G.T.; Shaw, C.Y. Air leakage data for the design of elevator and stair shaft pressurization systems. ASHRAE Trans. 1976, 82, 179-190. 
20. RDH Building Engineering Ltd. Study of Part 3 Building Airtightness; RDH Building Engineering Ltd.: Vancouver, BC, Canada, 2015.

21. Lstiburek, J.W. Toward an Understanding and Prediction of Air Flow in Buildings. Ph.D. Thesis, University of Toronto, Toronto, ON, Canada, 2000.

22. Gross, D.; Haberman, W. Estimating Air Leakage Through Doors for Smoke Control. Fire Saf. J. 1991, 17, 171-177. [CrossRef]

23. Tamura, G.T. Experimental Studies on Pressurized Escape Routes; National Research Council Canada: Ottawa, ON, Canada, 1974.

24. ASHRAE. ASHRAE Handbook Fundamentals; American Society of Heating, Refrigerating, and Air Conditioning Engineers: Atlanta, GA, USA, 2017.

25. Tamura, G.T. Review of the DBR/NRC studies on control of smoke from a fire in high buildings. ASHRAE Trans. 1983, 89, 341-361.

26. Proskiw, G.; Phillips, B. An examination of air pressure and air movement patterns in multi-unit residential buildings. In Proceedings of the Building Enclosure Science and Technology (BEST) Conference, Minneapolis, MN, USA, 12 June 2008.

27. ASHRAE. Tall Buildings. In 2015 ASHRAE Handbook—HVAC Applications; TC 9.12, Tall Buildings; ASHRAE: Atlanta, GA, USA, 2015.

28. Housing, B.C. Energy Use in Mid to High-Rise Multi-Unit Residential Buildings; Homeowner Protection Office: Burnaby, BC, Canada, 2013.

(C) 2019 by the authors. Licensee MDPI, Basel, Switzerland. This article is an open access article distributed under the terms and conditions of the Creative Commons Attribution (CC BY) license (http://creativecommons.org/licenses/by/4.0/). 